OPEN ACCESS

Edited by:

Jianhua Liu,

Second Affiliated Hospital of Jilin

University, China

Reviewed by:

Ajay Singh Karakoti

The University of Newcastle, Australia

Lei Wang,

Harbin Institute of Technology, China

*Correspondence:

Haiming Fan

fanhm@nwu.edu.cn

Specialty section: This article was submitted to

Nanoscience,

a section of the journal

Frontiers in Chemistry

Received: 08 January 2021

Accepted: 09 March 2021

Published: 27 April 2021

Citation:

Yu S, Zhang $H$, Zhang S, Zhong $M$ and Fan H (2021) Ferrite

Nanoparticles-Based Reactive Oxygen Species-Mediated Cancer Therapy. Front. Chem. 9:651053. doi: 10.3389/fchem.2021.651053

\section{Ferrite Nanoparticles-Based Reactive Oxygen Species-Mediated Cancer Therapy}

\author{
Shancheng $\mathrm{Yu}^{1}$, Huan Zhang ${ }^{2}$, Shiya Zhang ${ }^{1}$, Mingli Zhong ${ }^{3}$ and Haiming Fan ${ }^{1,2 *}$ \\ ${ }^{1}$ School of Biomedical Engineering and Informatics, Nanjing Medical University, Nanjing, China, ${ }^{2}$ College of Chemistry and \\ Materials Science, Northwest University, Xi'an, China, ${ }^{3}$ School of Public Health, Nanjing Medical University, Nanjing, China
}

Ferrite nanoparticles have been widely used in the biomedical field (such as magnetic targeting, magnetic resonance imaging, magnetic hyperthermia, etc.) due to their appealing magnetic properties. In tumor acidic microenvironment, ferrite nanoparticles show intrinsic peroxidase-like activities, which can catalyze the Fenton reaction of hydrogen peroxide $\left(\mathrm{H}_{2} \mathrm{O}_{2}\right)$ to produce highly toxic hydroxyl free radicals $(\bullet \mathrm{OH})$, causing the death of tumor cell. Recent progresses in this field have shown that the enzymatic activity of ferrite can be improved via converting external field energy such as alternating magnetic field and near-infrared laser into nanoscale heat to produce more $\bullet \mathrm{OH}$, enhancing the killing effect on tumor cells. On the other hand, combined with other nanomaterials or drugs for cascade reactions, the production of reactive oxygen species (ROS) can also be increased to obtain more efficient cancer therapy. In this review, we will discuss the current status and progress of the application of ferrite nanoparticles in ROS-mediated cancer therapy and try to provide new ideas for this area.

\section{Keywords: ferrite nanoparticles, reactive oxygen species, cancer therapy, fenton reaction, external field,} cascade reaction

\section{INTRODUCTION}

Cancer is one of the principal causes of morbidity and mortality in every country of the world. According to global cancer statistics of the World Health Organization, there were 18.1 million new cancer cases and 9.6 million cancer deaths in 2018, with the number of new cases rising $42.5 \%$ compared to that in 2008 (12.7 million) (Bray et al., 2018). In order to prevent the uncontrollable growth of tumor cells, the most conventional cancer therapeutic approaches used in clinical practice now are still surgery, chemotherapy, radiotherapy, and combination of them (Vahrmeijer et al., 2013; Barton et al., 2014; Prigerson et al., 2015; Sullivan et al., 2015; Sharma et al., 2016). However, surgery is often ineffective for advanced and metastasized cancers. Chemotherapy and radiotherapy suffer from severe side effects on account of the toxicity to normal cells and tissues. Based on the research of cancer-related biology and the development of biomedical engineering, a variety of alternative treatment strategies have been extensively studied to obtain more efficient cancer therapy, such as magnetic hyperthermia, photothermal therapy, photodynamic therapy, immunotherapy, and gene therapy (Dolmans et al., 2003; Yang et al., 2010; Kumar and Mohammad, 2011; Pardoll, 2012; Topalian et al., 2012; High and Roncarolo, 2019; Liu et al., 2019b). Most of these treatment strategies need to rely on the regulation of reactive oxygen species (ROS) to mediate tumor cell death. ROS are categorized as a class of incomplete reduction products of oxygen, mainly including superoxide anion $\left(\mathrm{O}_{2}^{-}\right)$, hydrogen peroxide $\left(\mathrm{H}_{2} \mathrm{O}_{2}\right)$, hydroxyl radical $(\bullet \mathrm{OH})$, 
and singlet oxygen $\left({ }^{1} \mathrm{O}_{2}\right)$ (Kumari et al., 2018). Superoxide anion can be generated as a byproduct of the electron transport chain in mitochondria or through activation of nicotinamide adenine dinucleotide phosphate oxidase (NOX) and exogenous stimulation (Murphy, 2009). Superoxide dismutase can reduce superoxide to hydrogen peroxide, which can be further converted into non-oxidizing water by cytosolic antioxidant systems under the catalysis of catalase, peroxiredoxins, and glutathione peroxidase (Winston and Giulio, 1991). The balance between the production and neutralization of reactive oxygen species in normal cells is beneficial to maintaining a proper ROS concentration to regulate intracellular signaling and homeostasis (Forman et al., 2010). Reactive oxygen species at high levels can damage proteins, lipids, and DNA, resulting in mutations and carcinogenesis in normal cells (Trachootham et al., 2009). Compared with normal cells, most tumor cells metabolize in distinct pathways leading to excessive ROS production (Schumacker, 2006). Cancer cells also have a higher level of antioxidant enzymes to enable them to survive in the presence of intrinsic oxidative stress without apoptosis (Birben et al., 2012). Increasing generation, regulating the types of reactive oxygen species, and inhibiting cellular glutathione peroxidase can break the balance between the production and elimination of ROS in tumor cell and tune the function of intracellular ROS from tumor promoting toward apoptotic signaling, inducing the apoptosis and death of tumor cell for cancer therapeutics (Liou and Storz, 2010). In order to enhance the effect of ROS-mediated tumor-specific therapeutic, various drugs and nanomaterials such as doxorubicin, cisplatin, $\mathrm{Fe}_{3} \mathrm{O}_{4}$, gold, silver, polyoxomolybdate (POM), and molybdenum carbide have been studied for targeted delivery to tumor tissues and endocytosis by tumor cells to selectively increase the production of highly toxic ROS in tumor cells (Yanagie et al., 2006; He et al., 2012, 2016b; Maji et al., 2015; Kankala et al., 2017; Feng et al., 2019; Liu et al., 2019a; Dong et al., 2020; Maiti et al., 2020). Among these nanomaterials, ferrite nanoparticles are widely studied due to unique magnetic properties and relatively high safety to human body, especially iron oxide nanoparticles, which have been approved by the US Food and Drug Administration for clinical applications, such as iron supplement, magnetic resonance contrast agent, and drug carrier (Liu et al., 2019c). Ferrite nanomaterials are composed of main ferric oxide and one or more oxides of other metals (such as manganese, copper, nickel, cobalt, or zinc). In tumor acidic microenvironment, ferrite nanoparticles exhibit peroxidase-like activity, which can catalyze the Fenton reaction of $\mathrm{H}_{2} \mathrm{O}_{2}$ to produce highly toxic $\bullet \mathrm{OH}$, inducing the death of tumor cell (Chen et al., 2012). The peroxidase activity depends on the intrinsic properties of ferrite nanoparticles (chemical composition, crystalline phase, and particle size) and ROS-related bio-microenvironmental factors (physiological $\mathrm{pH}$ and buffers, biogenic reducing agents, and other organic substances). For further reading these factors in detail, an excellent review has been published by Yin and colleagues ( $\mathrm{Wu}$ et al., 2014). In this review, we summarized the advances in the application of ferrite nanoparticles in ROSmediated cancer therapy, and constructive perspectives were also provided.

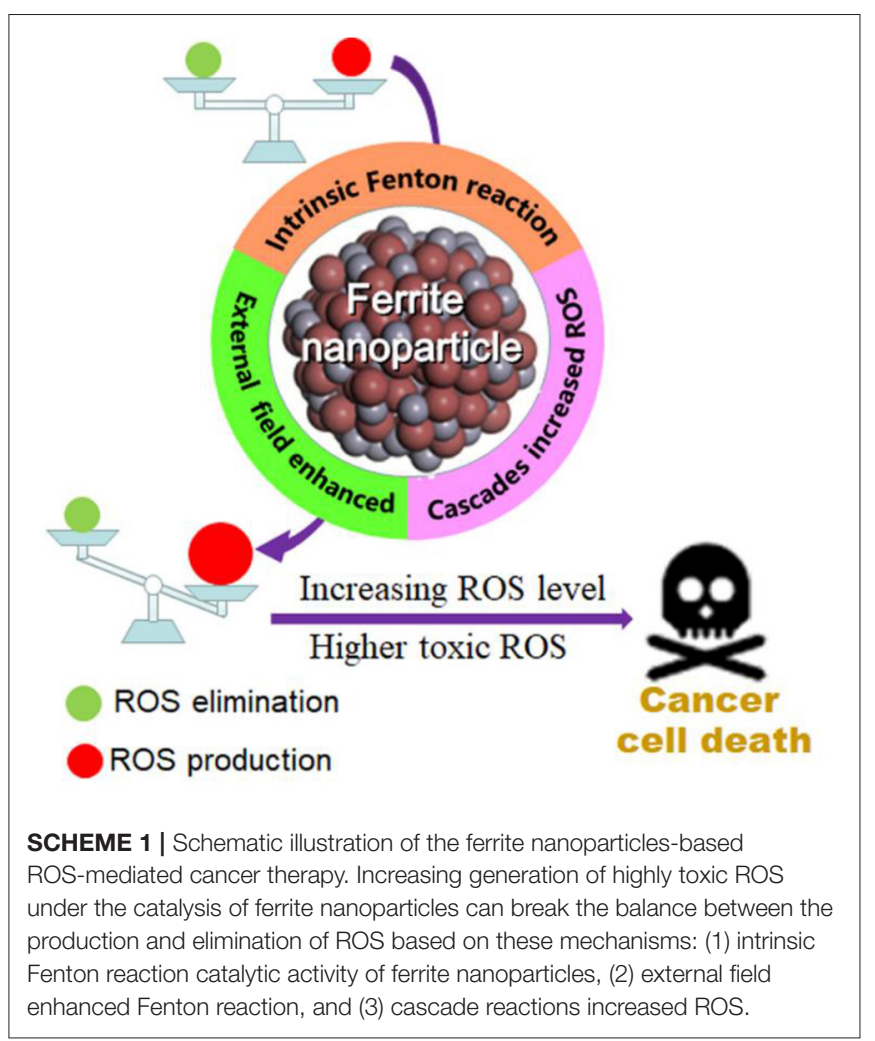

\section{FERRITE-BASED ROS-MEDIATED CANCER THERAPY}

In 2007, Yan et al. first discovered that $\mathrm{Fe}_{3} \mathrm{O}_{4}$ nanoparticles possess intrinsic peroxidase-like activity, which can catalyze the disproportionation of $\mathrm{H}_{2} \mathrm{O}_{2}$ to produce highly toxic $\bullet O H$ (Gao et al., 2007). Subsequently, researchers conducted extensive investigation on ferrite nanomaterials as nanoenzyme to mediate the generation of ROS for tumor treatment (Mai and Hilt, 2017). The specific mechanisms of the sufficient and highly toxic ROS production under the catalysis of ferrite nanoparticles in the existing publications can be roughly summarized as the following (shown in Scheme 1): (1) the intrinsic Fenton reaction catalytic activity of ferrite nanomaterials, (2) external field energy enhanced Fenton reaction, and (3) the cascade reactions to generate sufficient ROS.

\section{Intrinsic Fenton Reaction of Ferrite}

The intrinsic Fenton reaction catalytic activity is the most important mechanism of ferrite nanoparticles for ROS-mediated tumor therapy. Ferrite nanoparticles can specifically accumulate at the tumor site via enhanced permeability and retention effect and magnetic targeting and simultaneously release ferrous and ferric ions in tumor acidic environment to participate in the Fenton reaction with $\mathrm{H}_{2} \mathrm{O}_{2}$ and generate $\bullet O H$ (Wang et al., 2018). The Fenton and Fenton-like reactions can be shown as the following equations: $\mathrm{Fe}^{2+}+\mathrm{H}_{2} \mathrm{O}_{2} \rightarrow \mathrm{Fe}^{3+}+\mathrm{HO} \bullet+\mathrm{OH}^{-}$ (1); $\mathrm{Fe}^{3+}+\mathrm{H}_{2} \mathrm{O}_{2} \rightarrow \mathrm{Fe}^{2+}+\mathrm{HO}_{2}+\mathrm{H}^{+}$(2) (Bokare and Choi, 
2014). The intrinsic catalytic activity of ferrite nanoparticles can be flexibly designed and controlled by adjusting the particles composition, size, morphology, etc.

Wang et al. pioneered the study of magnetic nanoparticles for tumor treatment (Zhang et al., 2013). They synthesized 6 and $13 \mathrm{~nm}$ magnetite nanoparticles (MNPs) through a one-pot method, which possessed enzyme-mimicking activity to produce ROS efficiently for cancer theranostics. The smaller size MNPs had higher enzyme-mimicking activity, and an $99 \%$ tumor inhibition ratio was obtained by combining with intratumoral injection of exogenous hydrogen peroxide after treatment for 17 days. The size dependence of the catalytic activity of ferrite nanoparticles was further studied by Liu and colleagues. They investigated the cytotoxic effects of small $\mathrm{Fe}_{3} \mathrm{O}_{4}$ nanoparticles with different diameters $(6,9$, and $14 \mathrm{~nm})$ on human hepatoma cell lines, SK-Hep-1 and Hep3B (Xie et al., 2016). The 9 nm Fe ${ }_{3} \mathrm{O}_{4}$ nanoparticles mediated mitochondria-dependent intracellular ROS generation to induce cellular mitochondrial dysfunction and necrosis, while the $14 \mathrm{~nm} \mathrm{Fe}_{3} \mathrm{O}_{4}$ nanoparticles led to plasma membrane damage. Luo et al. obtained similar results that a suitable size $(15.1 \mathrm{~nm})$ of superparamagnetic iron oxide nanoparticles (SPIONs) enhanced the uptake amount into MCF7 cells, leading to the formation of more ROS (Zhang et al., 2020c). Promoted ROS was produced in mitochondria to destroy mitochondria by small size $(7.3 \mathrm{~nm})$ SPIONs, while more ROS was yield in plasma to destroy cytomembrane by larger size (15.1, $30.0 \mathrm{~nm}$ ) SPIONs. As can be seen from the above description, the size may affect the distribution of the nanoparticles. It would be more efficient if the ferrite nanoparticles can be delivered to the desired area. Zhu et al. developed a $\mathrm{pH}$-responsive iron oxides-loaded mesoporous silica nanosystem ( $\mathrm{FeO}_{\mathrm{x}}-\mathrm{MSNs}$ ), which could deliver $\mathrm{FeO}_{\mathrm{x}}$ to lysosomes and release $\mathrm{Fe}^{2+} / \mathrm{Fe}^{3+}$ in acidic environment to catalyze the decomposition of $\mathrm{H}_{2} \mathrm{O}_{2}$ to generate considerable ROS to damage breast carcinoma cells efficiently (Figure 1) (Fu et al., 2015).

The morphology has a significant impact on the properties of nanomaterials. $\mathrm{Li}$ et al. fabricated $\mathrm{Fe}_{3} \mathrm{O}_{4}$ nanoparticles with nanocluster, nanoflower, and nanodiamond structures by tuning the $\mathrm{pH}$ of the hydrothermal reaction (Figure 2) (Fu et al., 2017). The structure has a great influence on peroxidase-like activity, following the order of nanocluster $>$ nanoflower $>$ nanodiamond. However, nanodiamonds had the highest cellular endocytosis $(43.2,20.8$, and $18.8 \%$ of the added nanoparticles for nanodiamonds, nanoclusters, and nanoflowers, respectively). The cell viability data indicated that the cancer cell killing activity of the $\mathrm{Fe}_{3} \mathrm{O}_{4}$ nanoparticles was induced by the generated intracellular ROS through the Fenton reaction with $\mathrm{H}_{2} \mathrm{O}_{2}$, which was codetermined by the cell endocytosis of the nanoparticles and their enzyme-like activity.

Non-ferrous metal species such as copper, zinc, and iridium are widely used to regulate the performance of ferrite nanoparticles. Alshamsan et al. prepared copper ferrite nanoparticles, which could induce evident oxidative stress by ROS generation and glutathione depletion, triggering the death of human breast cancer MCF-7 cells (Ahamed et al., 2016). Liao et al. also incorporated copper into ferrite nanoparticles to regulate the $\mathrm{H}_{2} \mathrm{O}_{2}$ catalytic ability (Kuo et al., 2020). They changed the loading amount of iron precursor concentration to control the $\mathrm{Fe} / \mathrm{Cu}$ ratio of the CuFe NPs. The Combination of $\mathrm{Fe}$ and $\mathrm{Cu}$ in the oxide form could enhance the conversion of $\mathrm{H}_{2} \mathrm{O}_{2}$ to ROS, and the optimal Fe/Cu ratio was 2. Chuang et al. synthesized $\mathrm{SnFe}_{2} \mathrm{O}_{4}$ nanocrystals with sonication treatment, which could be delivered through inhalation for lung cancer therapy (Figure 3) (Lee et al., 2017). The lattice ferric ions can convert endogenous $\mathrm{H}_{2} \mathrm{O}_{2}$ into highly toxicity $\bullet \mathrm{OH}$ to effectively eradicate cancer cells through heterogeneous Fenton reaction. Wang et al. treated the cancer cells with iridium and $\mathrm{Fe}^{2+}$ ions to biosynthesize the biocompatible iridium oxide and iron oxide nanoclusters under the redox microenvironment (Shaikh et al., 2020). Their results demonstrated that U87 and HepG2 cells incubated with Ir-Fe significantly increased the ROS generation compared to Ir ions alone, triggering the apoptosis to inhibit tumor growth. Siddiqui et al. compared the cytotoxic activity of copper oxide $(\mathrm{CuO})$, iron oxide $\left(\gamma \mathrm{Fe}_{2} \mathrm{O}_{3}\right)$, and zinc, iron, and copper oxide $\left(\mathrm{CuZnFe}_{2} \mathrm{O}_{3}\right)$ in human breast cancer (MCF-7) cells (Siddiqui et al., 2020). The increase in ROS level could be important mechanism of metal oxide nanoparticlesinduced cytotoxicity in cancer cells. The above-mentioned results fully indicated that single and multimetal oxide nanoparticles exhibited differential cytotoxic responses in cancer cells, and the ROS production could be regulated by the chemical composition of nanomaterials.

Surface modification also plays an important role in the preparation, stability, and activity of ferrite nanoparticles. Tiku synthesized phyllanthus emblica-coated iron oxide nanoparticles (IONPAs) using a green approach (Thoidingjam and Tiku, 2019). The phyllanthus emblica could act as stabilizing agents by binding to the surfaces of the formed IONPs, so that IONPA was smaller in size with better dispersibility, leading to higher uptake in A549 lung cancer cells to produce more ROS to induce higher DNA damage and apoptosis. Small molecule coatings may significantly change the surface properties of the nanoparticles, which is needed to be considered in designing the nanoplatforms for cancer therapy. Hilt et al. observed that small molecule (citric acid, sodium phosphate, aminosilane, or dopamine) coatings could decrease surface reactivity of IONPs and inhibit ROS generation (Mai and Hilt, 2019). Conversely, Liu et al. reported that carboxy-functional $\mathrm{Fe}_{2} \mathrm{O}_{3}$ nanoparticles $\left(\mathrm{Fe}_{2} \mathrm{O}_{3} @ \mathrm{DMSA}\right)$ with negative zeta potential had higher cellular uptake efficiency, which promoted intracellular iron-retentioninduced ROS production but inhibited the fusion of lysosomes and autophagosomes to enhance tumoricidal autophagy for cancer therapy (Figure 4) (Xie et al., 2020). Ge et al. developed a novel ellipsoidal composite nanoplatform using a magnetic $\mathrm{Fe}_{3} \mathrm{O}_{4} / \mathrm{Fe}$ nanorod core enwrapped by a catalase-imprinted fibrous $\mathrm{SiO}_{2} /$ polydopamine shell $\left(\mathrm{Fe}_{3} \mathrm{O}_{4} / \mathrm{Fe} @ \mathrm{~F}-\mathrm{SiO}_{2} / \mathrm{PDA}\right)$ (Chen et al., 2017a). The catalase-imprinted shell can selectively inhibit the activity of catalase to elevate $\mathrm{H}_{2} \mathrm{O}_{2}$ level, which could be converted into $\bullet \mathrm{OH}$ under the catalysis of $\mathrm{Fe}$ ions released by $\mathrm{Fe}_{3} \mathrm{O}_{4} / \mathrm{Fe}$ core, triggering apoptosis to effectively kill MCF-7, 293T, and Hela tumor cells combined with the near-infrared light photothermal effect of the polydopamine layer. Targeting and responsive molecules assembled on the surface of nanoparticles can improve delivery efficiency and selectivity. Horak et al. 
A
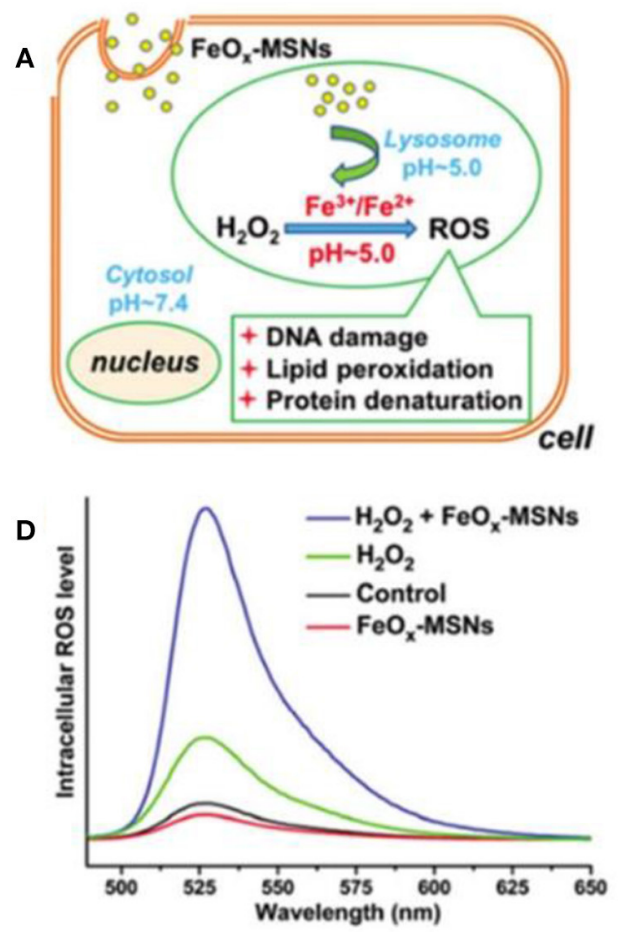
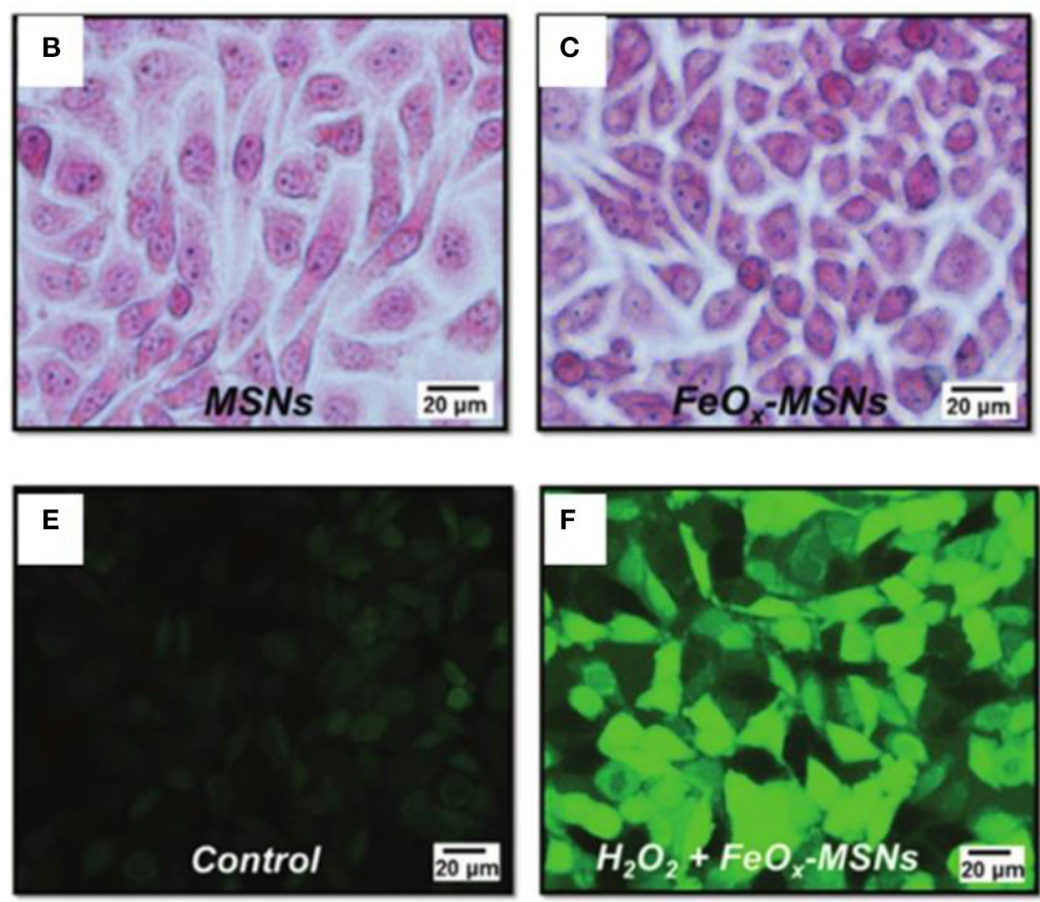

FIGURE 1 | (A) Illustration of interactions of $\mathrm{FeO}_{x}-\mathrm{MSN}$ and $\mathrm{H}_{2} \mathrm{O}_{2}$. Turnbull's blue stain of ZR75-30 cells after incubation with (B) MSNs and (C) FeO $-\mathrm{MSNs}$. (D) Fluorescence emission spectra of DCF in ZR75-30 cells after incubation with FeO $-\mathrm{MSNs}_{\mathrm{x}}$ and/or $\mathrm{H}_{2} \mathrm{O}_{2}$. Fluorescence images of ZR75-30 cells in the (E) control and (F) $\mathrm{FeO}_{x}-\mathrm{MSN}$ plus $\mathrm{H}_{2} \mathrm{O}_{2}$ groups. Reproduced, with permission, from Fu et al. (2015). Copyright 2015, Royal Society of Chemistry.

prepared magnetic and temperature-sensitive solid lipid particles (mag. SLPs) using oleic acid-coated iron oxide, 1-tetradecanol, and poly(ethylene oxide)-block-poly(E-caprolactone), which could melt down in the tumorous tissue to produce more ROS than the non-magnetic SLPs and neat iron oxides, inducing apoptosis of Jurkat leukemic cells (Swietek et al., 2020). Sawant et al. developed novel $\mathrm{pH}$ responsive and mitochondria targeted poly-l-lysine-coated $\mathrm{Fe}_{3} \mathrm{O}_{4} @ \mathrm{FePt}$ core shell nanoparticles (Mito-PANPs) (Pandey et al., 2020). Mitochondria directing triphenylphsphonium ion mediated the delivery of nanoparticles to mitochondria, enhancing ROS generation to provide multimodal therapy for glioblastomas. The gradient core-shell structure is widely used to modify the surface of functional nanomaterials. Hou et al. developed a $\mathrm{pH}$-sensitive nanoreactor based on core-shell-structured iron carbide nanoparticles with amorphous $\mathrm{Fe}_{3} \mathrm{O}_{4}$ shells $\left(\mathrm{Fe}_{5} \mathrm{C}_{2} @ \mathrm{Fe}_{3} \mathrm{O}_{4}\right)$. The amorphous $\mathrm{Fe}_{3} \mathrm{O}_{4}$ shells were less stable against dissolution and able to release ferrous ions in acidic environments to generate $\bullet \mathrm{OH}$ through the Fenton reaction of $\mathrm{H}_{2} \mathrm{O}_{2}$, effectively inhibiting the proliferation of tumor cells (Yu et al., 2019).

The effect of ROS-mediated tumor therapy can be significantly improved by combining ferrite nanoparticles with chemotherapeutic drugs, chemical or biological agents, etc. Bahadur et al. developed PEGylated mesoporous iron platinum-iron oxide composite nanoassemblies with high loading capacity of doxorubicin, which exhibited a higher efficiency of ROS generation compared to $\mathrm{Fe}_{3} \mathrm{O}_{4}$ and $\mathrm{Pt}$ under the synergistic catalytic effect of $\mathrm{FePt}$ and $\mathrm{Fe}_{3} \mathrm{O}_{4}$, resulting in efficient chemo- and thermal therapy for Hela cancer cells (Sahu et al., 2015). Yeh et al. presented an $\mathrm{H}_{2} \mathrm{O}_{2}$-loaded ultrasound contrast agent $\mathrm{H}_{2} \mathrm{O}_{2} / \mathrm{Fe}_{3} \mathrm{O}_{4}$-poly(D,L-lactideco-glycolic acid (PLGA) polymersome, which could yield sufficient $\bullet \mathrm{OH}$ through the Fenton reaction of encapsulated $\mathrm{H}_{2} \mathrm{O}_{2}$ and $\mathrm{Fe}_{3} \mathrm{O}_{4}$, completely removing the malignant tumors in a non-thermal process ( $\mathrm{Li}$ et al., 2016). Watanabe et al. investigated the combined effects of $\mathrm{Fe}_{3} \mathrm{O}_{4}$ nanoparticles with chemotherapeutic agents (rapamycin or carboplatin) on prostate cancer cells in vitro (Kojima et al., 2018). Synergistic effect of $\mathrm{Fe}_{3} \mathrm{O}_{4}$ NPs was observed in DU145 cells with carboplatin and in PC-3 cells with rapamycin, increasing intracellular ROS levels to decrease cancer cell viability significantly. Hou et al. designed a PLGA-polymer matrix coated with $\mathrm{Fe} / \mathrm{FeO}$ core-shell nanocrystals and coloaded with chemotherapy drug and photothermal agent (DOX-ICG@Fe/FeO-PPP-FA nanocapsules), which could in situ overproduce ROS by reacting with endogenous $\mathrm{H}_{2} \mathrm{O}_{2}$ in tumors, overcoming the tumor hypoxia-related resistance of chemotherapy and photodynamic therapy (Figure 5) (Wang et al., 2019c). Liu et al. developed a facile synergistic nanoplatform (NanoTRAIL) using iron oxide cluster and tumor necrosis factor-related apoptosis-inducing ligand (TRAI/Apo2L), which could release iron oxide NPs to generate ROS to provoke JNK-autophagy-dependent DR5 

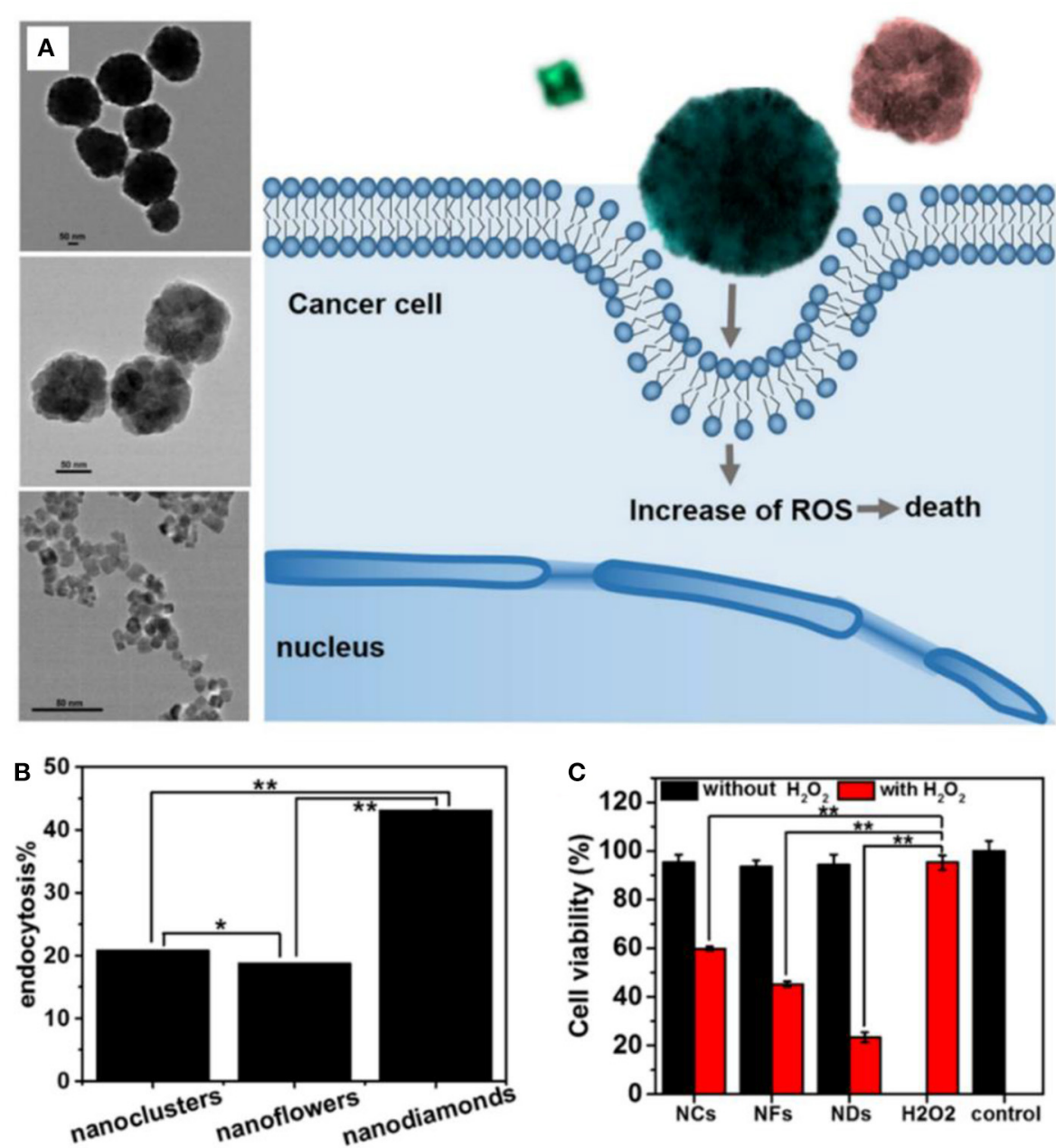

FIGURE 2 | (A) Schematic illustration for the structural effect of $\mathrm{Fe}_{3} \mathrm{O}_{4}$ nanoparticles on ROS generation for cancer cell killing. (B) Endocytosis percentage of three kinds of $\mathrm{Fe}_{3} \mathrm{O}_{4}$ nanoparticles. (C) Cell viability incubated with $\mathrm{Fe}_{3} \mathrm{O}_{4}(1 \mathrm{mg} / \mathrm{ml})$ alone or $\mathrm{Fe}_{3} \mathrm{O}_{4}(25 \mu \mathrm{g} / \mathrm{ml})$ plus $\mathrm{H}_{2} \mathrm{O}_{2}(0.625 \mu \mathrm{M})$. Statistical significance, ${ }^{\star} p<0.05,{ }^{\star \star} p<0.01$. Reproduced, with permission, from Fu et al. (2017). Copyright 2017, Elsevier.

upregulation, leading to enhancing TRAIL/Apo2L-induced apoptosis in colorectal cancer (Shi et al., 2020). Thenmozhi prepared PVP-coated iron oxide nanoparticles loaded with syzygium aromaticum extract, which could induce oxidative stress via ROS formation, enhancing MCF-7 breast cancer apoptosis (Thenmozhi, 2020). This interesting study of the application of biomass syzygium aromaticum extract can provide a useful reference for the application researches of traditional Chinese medicine.

The applicability of ROS-mediated treatment to different types of cancers has been extensively verified. Ahamed et al. prepared spherical iron oxide nanoparticles with a smooth surface and an average diameter of $23 \mathrm{~nm}$, which could induce the reactive oxygen species generation in HepG2 and A549 cancer cells, upregulating tumor suppressor gene p53 and caspase-3 and caspase-9 apoptotic genes to trigger cancer cells apoptosis (Ahamed et al., 2013). In subsequent research, they found that the MCF-7 cells were slightly more sensitive to nickel ferrite nanoparticles than liver HepG2 cells induced by reactive oxygen species (Ahamed et al., 2015). Gokduman synthesized magnetite iron oxide nanoparticles with a diameter of $\sim 20 \mathrm{~nm}$, which could increase intracellular ROS, enhancing the anticancer activity of cisplatin by increasing the apoptosis of the cisplatin-resistant ovarian cancer cells (OVCAR3 and SKOV-3) (Gokduman, 2019). Rajesh et al. developed a hybrid magnetic microsphere system $\left(\mathrm{Fe}_{3} \mathrm{O}_{4} @ L E C-C U R-P L G A-\right.$ MMS) using iron oxide nanoparticle $\left(\mathrm{Fe}_{3} \mathrm{O}_{4} \mathrm{NP}\right)$, lecithin (LEC), curcumin (CUR), PLGA, and polyethylene glycol (PEG) (Ayyanaar et al., 2020). The $\mathrm{Fe}_{3} \mathrm{O}_{4}$ could catalyze the generation of ROS in an $\mathrm{H}_{2} \mathrm{O}_{2}$ environment to release the CUR, showing greater cytotoxicity against A549 and HeLa S3 cells. Salehzadeh et al. synthesized $\mathrm{Fe}_{3} \mathrm{O}_{4} @ \mathrm{CPTMOS} / \mathrm{TP}$ NPs, which had an effect on induction of apoptosis and inhibition of the growth of gastric AGS cancer cells by increasing ROS production in the treated cells (Habibzadeh et al., 2020). The $\mathrm{IC}_{50}$ value in AGS cells was estimated to be $95.65 \mu \mathrm{g} / \mathrm{ml}$. Ramalingam et al. prepared 


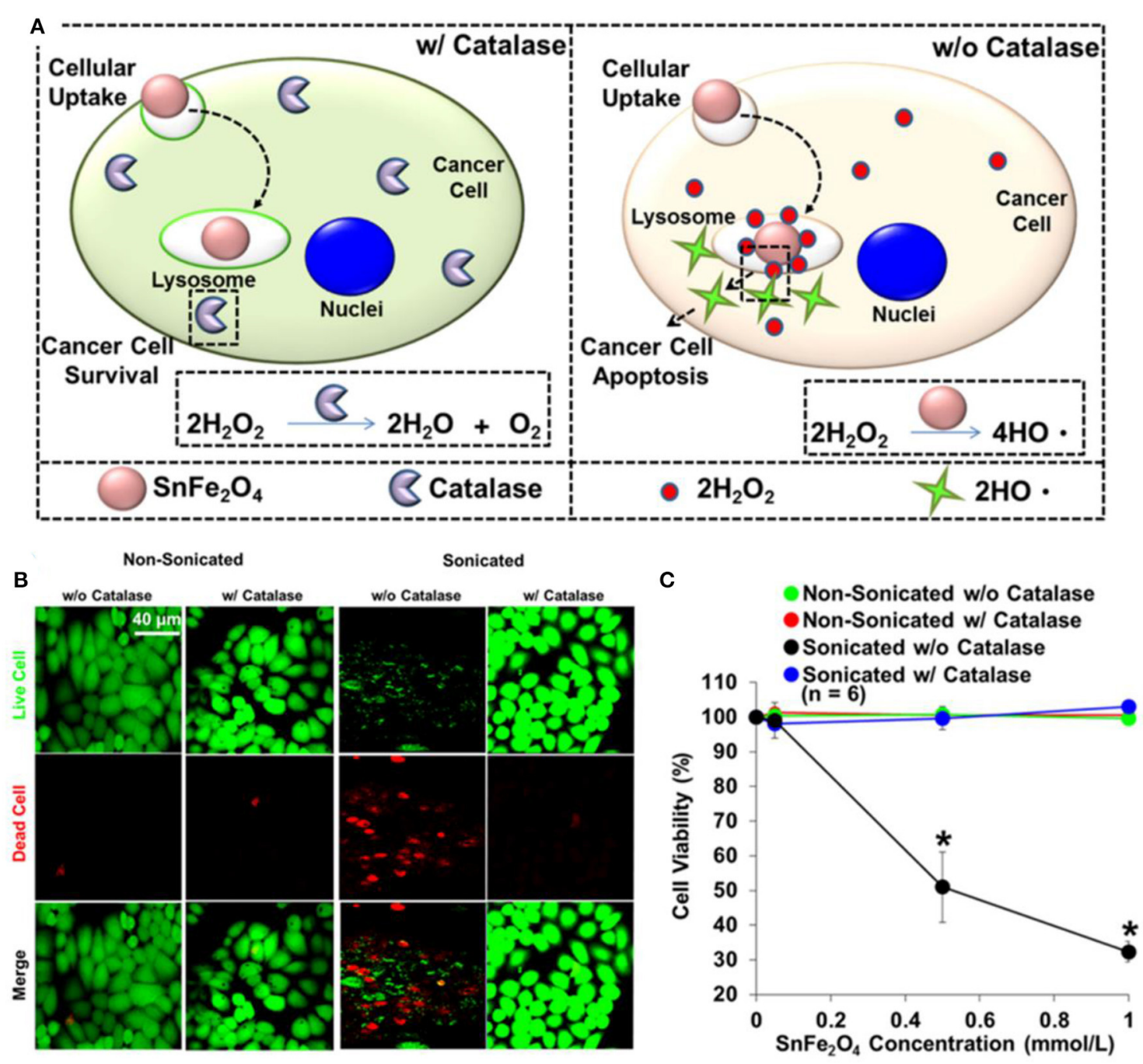

FIGURE 3 | (A) Illustration for cytotoxic effect of $\mathrm{SnFe}_{2} \mathrm{O}_{4}$ nanocrystals on cancer cells. (B) Fluorescent images of test cells. (C) Corresponding quantitative results obtained using MTT. *Statistical significance indicated by $P<0.05$. Reproduced, with permission, from Lee et al. (2017). Copyright 2016, American Chemical Society.

hematite $\alpha-\mathrm{Fe}_{2} \mathrm{O}_{3}$ by wet chemical method, which showed dose-dependent anticancer activity against human metastatic ovarian cancer (OC) by inducing ROS generation, damaging the mitochondrial membrane, and triggering the apoptosis of OC PA-1 cells (Ramalingam et al., 2020). Pourahmad et al. investigated the effect of SPIONs on the oral tongue squamous cell carcinoma (OTSCC) (Jahanbani et al., 2020). SPIONs were able to increase the level of ROS formation in cancerous mitochondria to selectively initiate ROS-mediated apoptosis of SCC cells. As can be seen from the above descriptions, ROSmediated therapies based on ferrite nanoparticles have broad applicability to a wide range of cancers.

The study of mechanisms and pathways for ROS-mediated cancer therapy based on ferrite nanoparticles has also attracted the attention of researchers. Liu et al. investigated the molecular mechanism of SPIONs induced cancer-cell-specific cytotoxicity through DNA microarray and bioinformatics analyses ( $\mathrm{He}$ et al., 2016a). SPIONs can interfere with the mitochondrial electron transport chain to induce the formation of ROS, triggering cytotoxicity to the cancer cells. Han et al. reported that ultrasmall $9 \mathrm{~nm} \mathrm{Fe}_{3} \mathrm{O}_{4}$ NPs could effectively internalize into cells and locate in the nucleus and induce ROS production and oxidative damage by disturbing the expression of antioxidantrelated genes, suggesting a potential antitumor application (Ye et al., 2020). Ma et al. demonstrated polyethyleneiminecoated $\mathrm{Fe}_{3} \mathrm{O}_{4}$ magnetic nanoparticles (PEI-MNPs), which could contribute to ROS overproduction by the Fenton reaction, resulting in autophagy induction via mTOR-Akt-p70S6 K and ATG7 signaling pathways to kill cancer cells (Figure 6) (Man et al., 2020). Further research on the mechanism will be beneficial to the development of more effective ferrite nanoparticle-based therapeutic agents. 

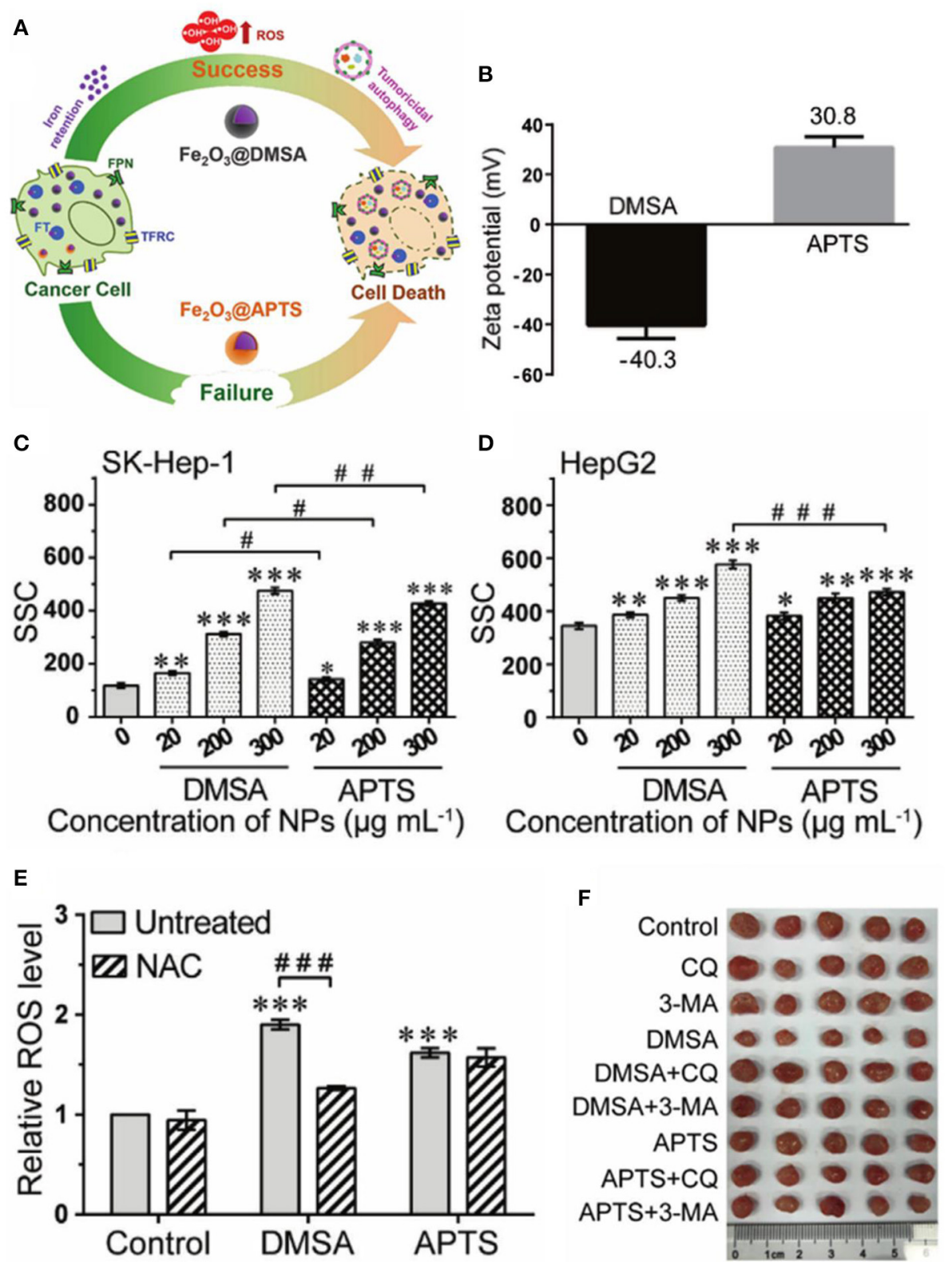

FIGURE 4 | (A) Schematic illustration for $\mathrm{Fe}_{2} \mathrm{O}_{3} @ D M S A$ promoted ROS-induced tumoricidal autophagy. (B) Zeta potential of Fe $\mathrm{O}_{3} @ D M S A$ and Fe $\mathrm{O}_{3} @ A P T S$. (C,D) Cellular uptake of $\mathrm{Fe}_{2} \mathrm{O}_{3} @ D M S A$ and $\mathrm{Fe}_{2} \mathrm{O}_{3} @ A P T S$. (E) ROS production of SK-Hep-1 cells exposed to Fe $\mathrm{O}_{2} \mathrm{O}_{3} @ D M S A$ or Fe $\mathrm{O}_{3} @ A P T S$. (F) Photographs of tumors. Statistical significance, ${ }^{\star} p<0.05,{ }^{\star *} p<0.01$, and ${ }^{\star \star *} p<0.001$ compared with control. $\# p<0.05$, \#\# $p<0.01$, and \#\#\# $p<0.001$ between the indicated groups Reproduced, with permission, from Xie et al. (2020). Copyright 2020, WILEY-VCH Verlag GmbH \& Co. KGaA, Weinheim

\section{External Field Enhanced Fenton Reaction}

Only relying on the intrinsic Fenton reaction catalytic activity of ferrite nanomaterials often requires a high concentration to generate enough ROS to kill tumor cells, which may increase the burden of iron removal based on the kidney and liver and cause adverse damage to the body (Ranji-Burachaloo et al., 2018). External electromagnetic waves such as X-ray, near-infrared light and alternating magnetic field can be absorbed by the ferrite-based nanoplatform to improve the production of reactive oxygen species (Laurent et al., 2011; Pilar Vinardell and Mitjans, 2015; Xiong et al., 2019). Ultrasound, a typical high-frequency mechanical wave, can also be used as an external energy source. Gorgizadeh et al. synthesized a nickel ferrite/carbon nanocomposite $\left(\mathrm{NiFe}_{2} \mathrm{O}_{4} / \mathrm{C}\right)$ as sonosensitizer (Gorgizadeh et al., 2019). Radiation of ultrasound into $\mathrm{NiFe}_{2} \mathrm{O}_{4} / \mathrm{C}$ effectively induced cavitation formation and ROS production, resulting in remarkable efficacious recovery in mouse melanoma cancer model by intratumorally injection at dosage of $\sim 100 \mathrm{mg} \mathrm{kg}^{-1}$. 


\section{A}

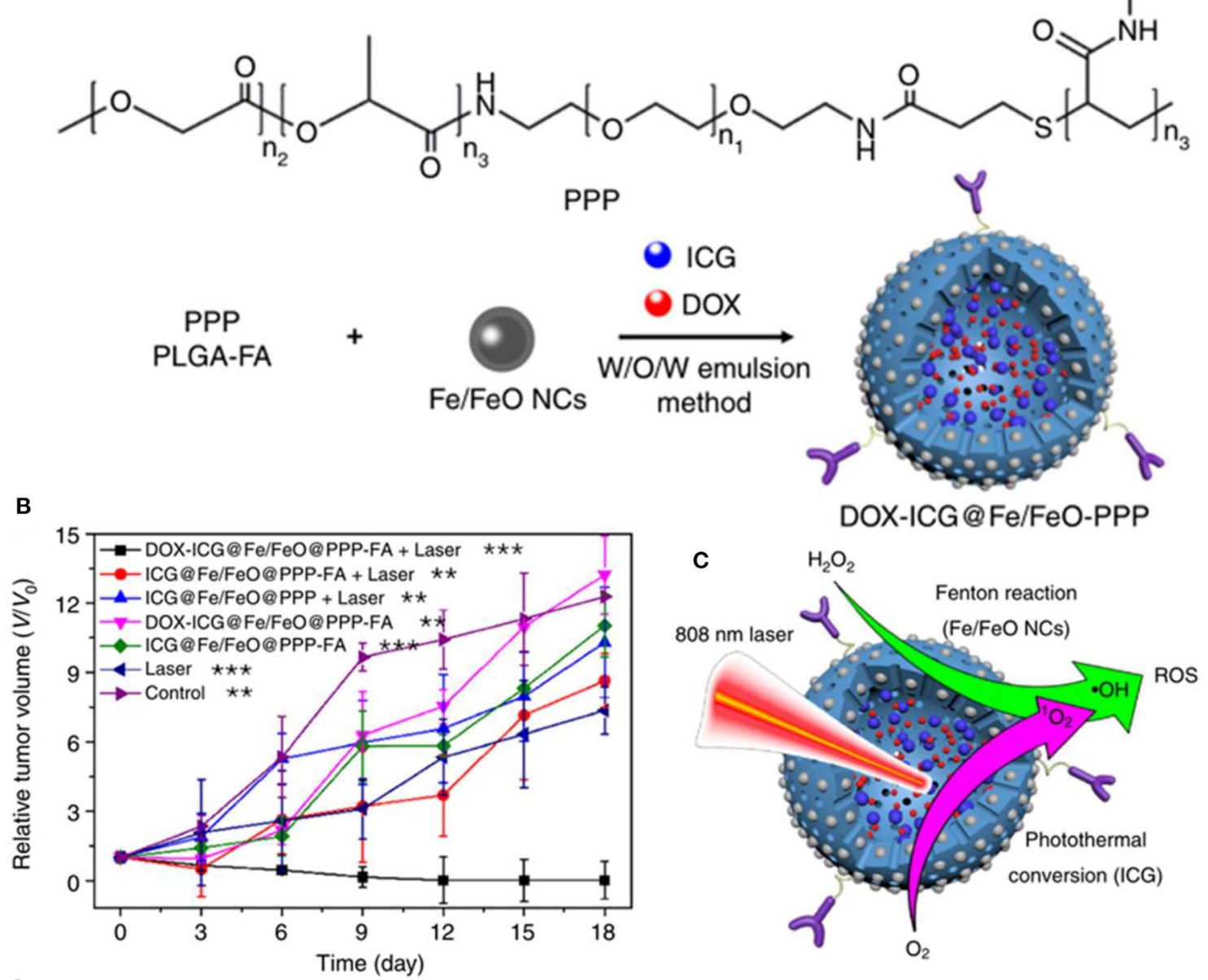

FIGURE 5 | (A) Fabrication of DOX-ICG@Fe/FeO-PPP nanocapsules. (B) Volume change of tumor in different treatments. (C) Synergism schematic of Fenton reaction of $\mathrm{Fe} / \mathrm{FeO} \mathrm{NCs}$ with photothermal conversion (ICG). ${ }^{* \star} p<0.01,{ }^{* \star} p<0.001$. Reproduced, with permission, from Wang et al. (2019c). Copyright 2019, Nature Publishing Group.

Kryschi et al. first studied the citrate-coated superparamagnetic iron oxide nanoparticles as X-ray radiosensitizer (Klein et al., 2012). The increased catalytically active iron oxide nanoparticle surfaces can enhance the ROS generation for about $240 \%$ under the X-ray exposure. In subsequent research, they synthesized 9-20 nm $\left(\gamma \mathrm{Fe}_{2} \mathrm{O}_{3}\right)_{1-x}\left(\mathrm{Fe}_{3} \mathrm{O}_{4}\right)_{x}$ surface stabilized with citrate or malate anions, which can drastically enhance the ROS concentration of more than $300 \%$ via the Fenton reaction in $1 \mathrm{~Gy} \mathrm{X}$-rayirradiated tumor cells (Klein et al., 2014). Hadjipanayis et al. showed that cetuximab-conjugated iron oxide nanoparticles (cetuximab-IONPs) could sensitize ionizing radiation therapy by increasing ROS formation and DNA double strands breaks (Bouras et al., 2015). Hilt et al. developed a cell-penetrating peptide functionalized iron oxide nanoparticle (TAT- $\mathrm{Fe}_{3} \mathrm{O}_{4}$ ) to increase the efficacy of radiation therapy (Hauser et al., 2016b). Radiation promoted the production of the superoxide anion in mitochondria, which was further converted to hydrogen peroxide by superoxide dismutase, and the generated $\mathrm{H}_{2} \mathrm{O}_{2}$ could be catalyzed to the highly reactive hydroxyl radical by the Fenton reaction with iron oxide nanoparticles for the enhancement of radiation therapy. Kryschi et al. synthesized functionalized superparamagnetic magnetite $\left(\mathrm{Fe}_{3} \mathrm{O}_{4}\right)$ and $\mathrm{Co}-$ ferrite $\left(\mathrm{CoFe}_{2} \mathrm{O}_{4}\right)$ nanoparticles with self-assembled monolayer coatings, which have long-term stability and could be activated through X-ray exposure with a single dosage of $1 \mathrm{~Gy}$ to induce ablation of the surface coverage and release either $\mathrm{Fe}^{2+}$ or $\mathrm{Co}^{2+}$ ions, enhancing the production of the highly hydroxyl radical via the Fenton reaction to kill the cancerous MCF-7 cells efficiently (Figure 7) (Klein et al., 2018).

Light waves are also widely used as external field energy sources. Near-infrared light irradiation can be efficiently converted into heat to enhance ROS generation. Miao et al. synthesized $\mathrm{Zn}^{2+}$-doped magnetic nanoparticles via hydrothermal route, which revealed excellent photothermal effect to generate localized heat and increase the dissolution of magnetic nanoparticles in the acid medium to enhance ROS generation upon a near-infrared (NIR) light irradiation, inducing 
A

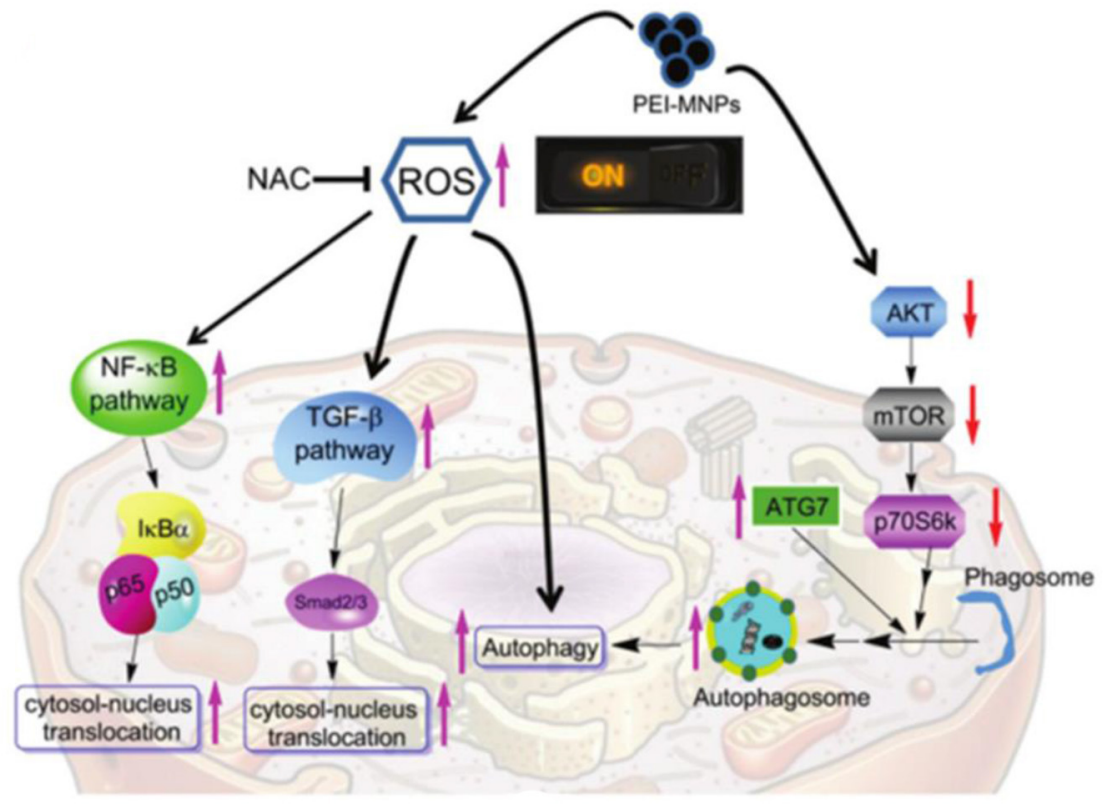

B

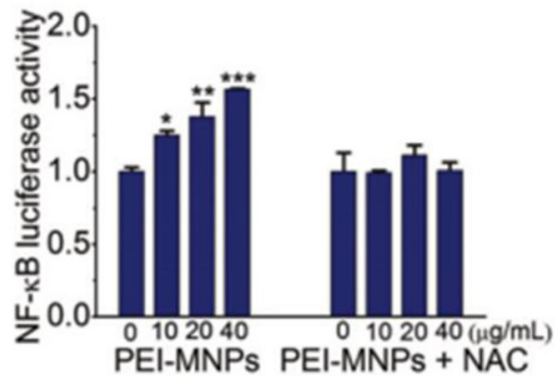

C

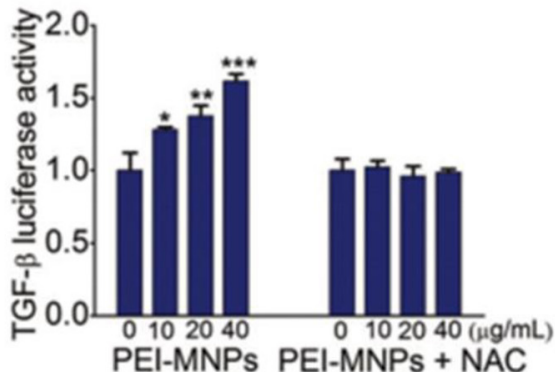

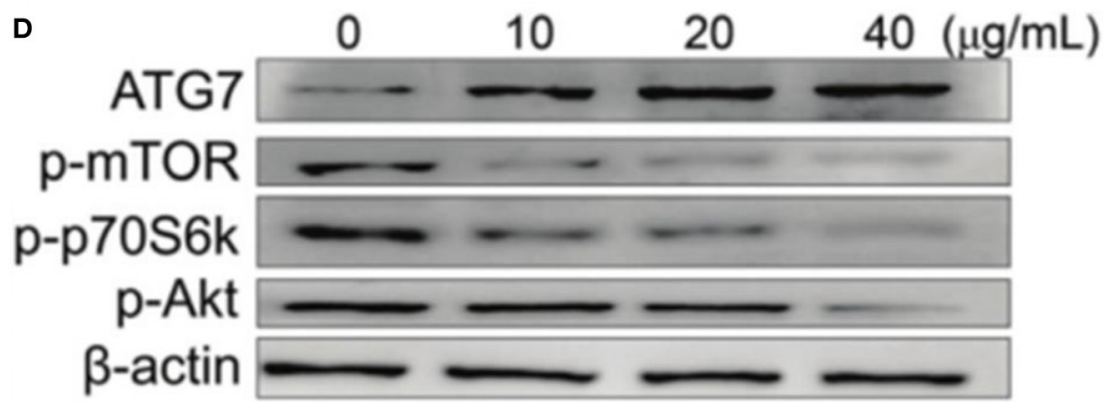

FIGURE 6 | (A) Schematic illustration for roles of ROS on PEI-MNPs elicited responses in cancer cells. (B,C) PEI-MNPs induced overproduction of ROS, triggering the activation of NF-kB and TGF- $\beta$ pathways. (D) Western blotting experiments of the cancer cells treated with PEI-MNPs. ${ }^{\star} P<0.05 ;{ }^{\star \star} P<0.01 ;{ }^{\star \star \star} P<0.005$ vs controls. Reproduced, with permission, from Man et al. (2020). Copyright 2020, Royal Society of Chemistry.

cancer treatment (Qi et al., 2016). Chen et al. confirmed that the bacterial magnetic nanoparticles could induce increased level of intracellular ROS along with heat under near-infrared light irradiation to trigger an efficient tumor cell kill (Chen et al., 2016). Dong et al. fabricated a nanoplatform based on iron oxide nanoparticles, indocyanine green, and hyaluronic acid (IONPs-ICG-HA) (Wang et al., 2019a). The iron oxide could convert intracellular $\mathrm{H}_{2} \mathrm{O}_{2}$ to generate fatal reactive oxygen species through Fenton reaction, which could be boosted by increased temperature of photothermal effect of ICG, enhancing synergistic phototherapy in cancer treatment. Li et al. developed a tumor-targeting iron sponge $\gamma$ GDYO- $\mathrm{Fe}_{3} \mathrm{O}_{4}$-CREKA (TTIS) nanocomposite, which could accelerate the release of iron ions to enhance the efficiency of the Fenton reaction and generate 


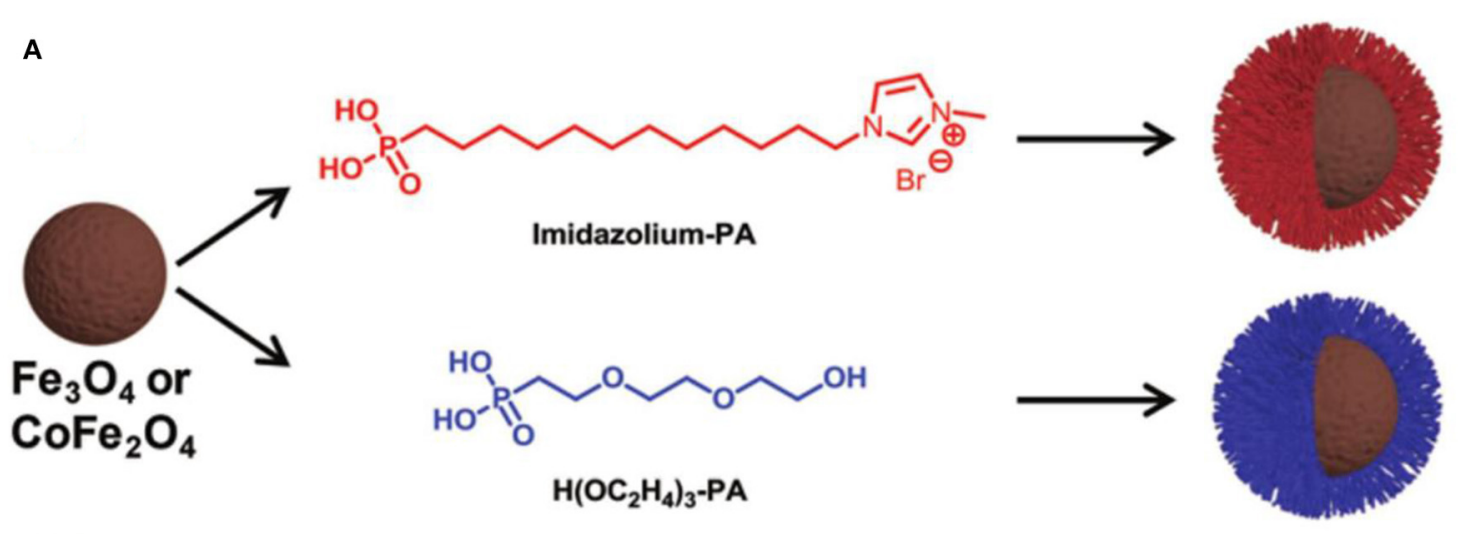

B
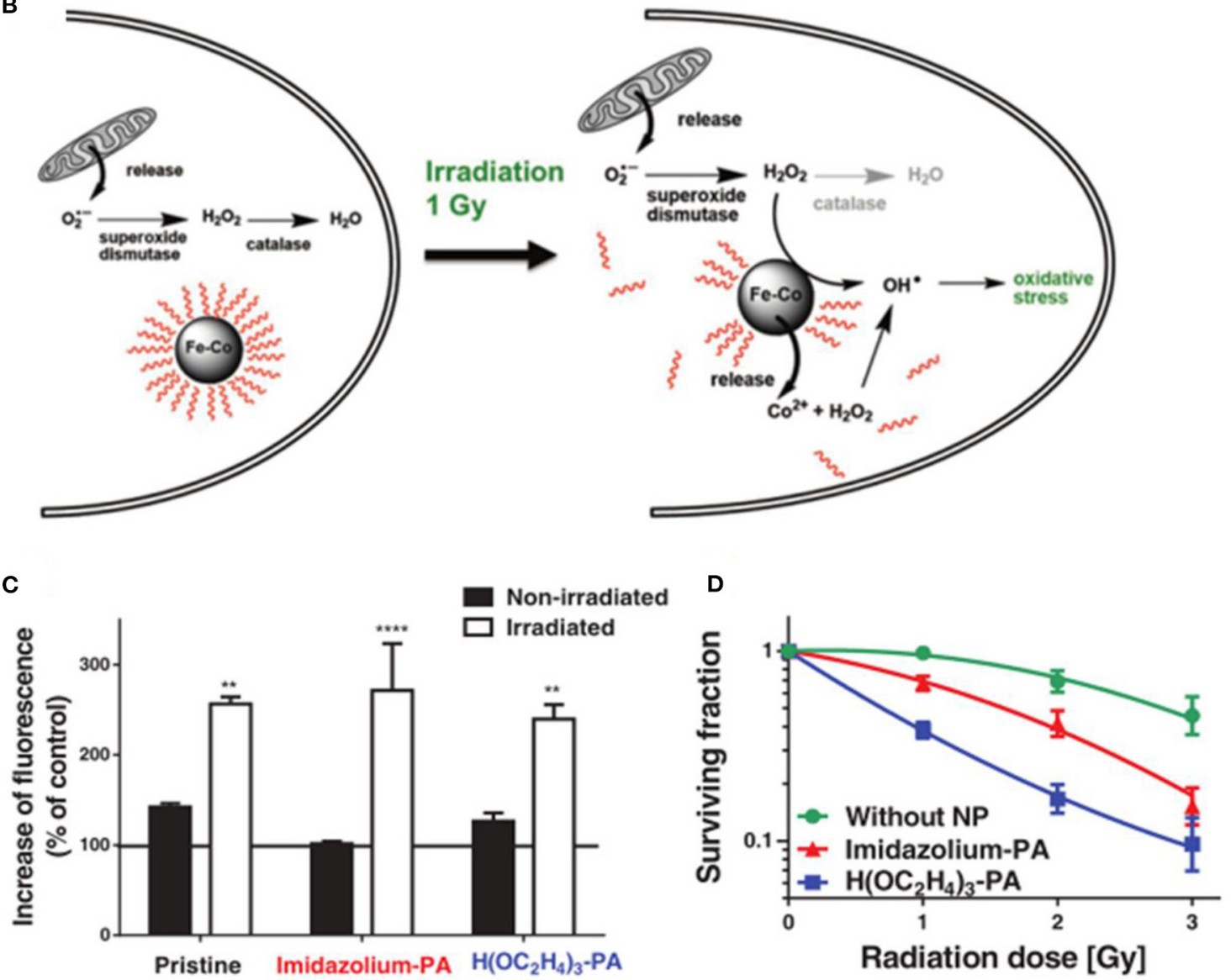

FIGURE 7 | (A) Fabrication of PA-SAM functionalized $\mathrm{Fe}_{3} \mathrm{O}_{4}$ and $\mathrm{CoFe}_{2} \mathrm{O}_{4}$ MNPs. (B) Mechanisms of ROS generation under X-ray irradiation. (C) Determination of ROS concentration in MCF-7 cells. (D) Survival curves of MCF-7 cells incubated with functionalized $\mathrm{CoFe}_{2} \mathrm{O}_{4}$ MNPs. ${ }^{* \star} P<0.01,{ }^{* \star \star *} P<0.001$. Reproduced, with permission, from Klein et al. (2018). Copyright 2018, WILEY-VCH Verlag GmbH \& Co. KGaA, Weinheim.

more ROS by the heat produced in the process of photothermal therapy (Min et al., 2020). You et al. designed a more stable and high-ROS-yielding $\mathrm{Pt} / \mathrm{Fe}_{3} \mathrm{O}_{4} @ S P-P L G A$ lipo-polymersom, which could significantly increase the generation of $\bullet \mathrm{OH}$ for ROS-mediated cancer therapy through the reaction between succinic peroxide (SP) and iron oxide under NIR irradiation (You et al., 2019). Photosensitizers can be activated by laser irradiation to improve the electron-hole pairs separation efficacy and redox potentials, leading to strong ability in generating ROS. Ji et al. prepared 2D ultrathin Z-scheme highly oxidized ilmenite nanosheets $\left(\mathrm{FeTiO}_{3} @ \mathrm{Fe}_{2} \mathrm{O}_{3}\right)$ with much strong oxidation and reduction potentials in the valence band (VB) of $\mathrm{Fe}_{2} \mathrm{O}_{3}$ and the conduction band (CB) of $\mathrm{FeTiO}_{3}$, which could enhance the generation of $\mathrm{O}_{2}^{-}$from $\mathrm{O}_{2}$ on the $\mathrm{CB}$ of $\mathrm{FeTiO}_{3}$ and $\bullet \mathrm{OH}$ 
A

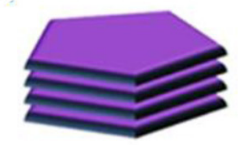

IL powder $\left(\mathrm{FeTiO}_{3}\right)$

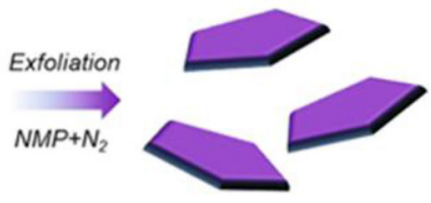

IL NSs $\left(\mathrm{FeTiO}_{3}\right)$
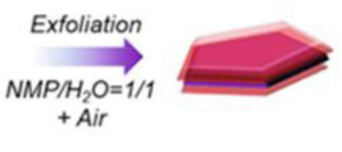

HOIL NSs $\left(\mathrm{FeTiO}_{3} @ \mathrm{Fe}_{2} \mathrm{O}_{3}\right)$

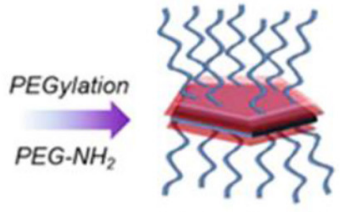

HOIL.PEG NSS $\left(\mathrm{FeTiO}_{3} @ \mathrm{Fe}_{2} \mathrm{O}_{3}\right)$
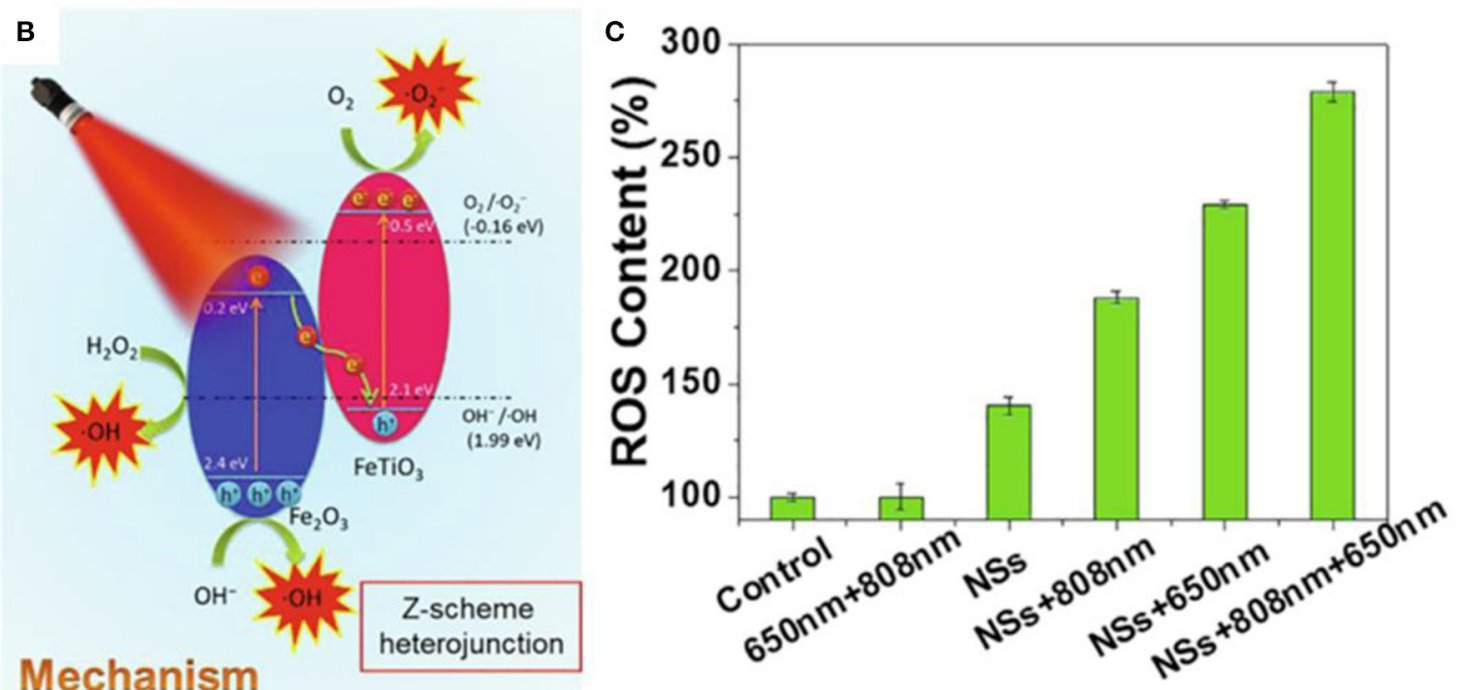

D

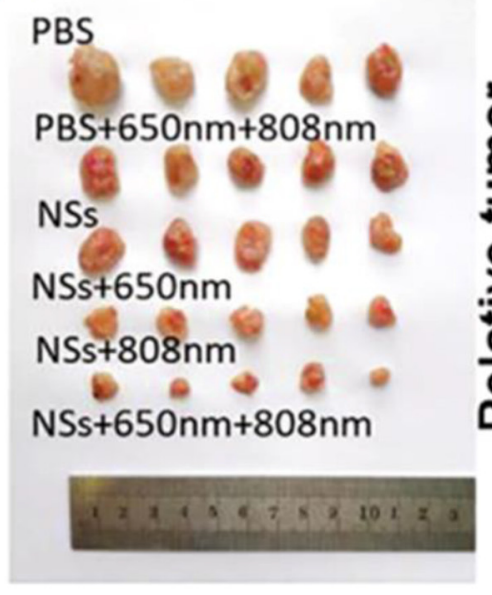

E

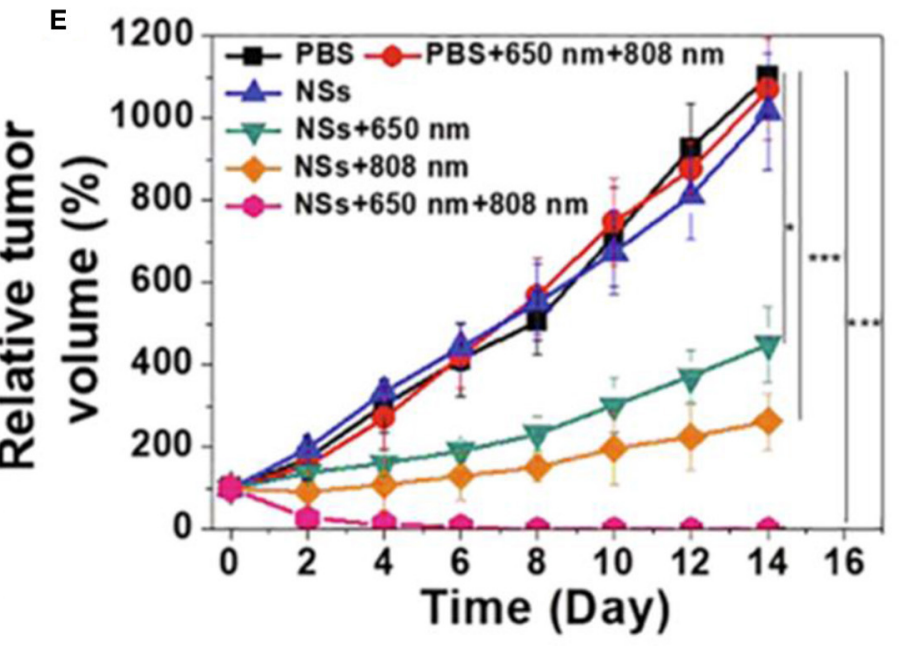

FIGURE 8 | (A,B) Schematic illustration of fabrication and therapy mechanism of HOIL-PEG NSs. (C) ROS content of A549 cells after treated. (D) Morphology of representative tumors. (E) Tumor volume of A549 tumor-bearing nude mice after treatment. Statistical values are indicated in figures according to the following scale: ${ }^{\star} P<0.05,{ }^{\star *} P<0.01$ and ${ }^{\star \star *} P<0.001$. Reproduced, with permission, from Ou et al. (2020). Copyright 2020, Elsevier.

from $\mathrm{H}_{2} \mathrm{O}_{2}$ on the $\mathrm{VB}$ of $\mathrm{Fe}_{2} \mathrm{O}_{3}$ for antitumor therapy under irradiation of $650 \mathrm{~nm}$ laser (Figure 8) (Ou et al., 2020).

Ferrite nanoparticles have unique magnetic heating transfer efficiency to generate heat, enhancing the effect of ROS-mediated cancer therapy (Johannsen et al., 2010; Silva et al., 2011). The alternating magnetic field is the most commonly used due to its large penetration. Hilt et al. showed that peptide-conjugated magnetic nanoparticles (TAT-IONP) could increase cellular ROS generation in both A549 and H358 cell lines upon exposure to an alternating magnetic field, resulting in an increase in apoptosis via the Caspase 3/7 pathways (Hauser et al., 2016a). Orel et al. designed magnetic nanodots composed of doxorubicinloaded $\mathrm{Fe}_{3} \mathrm{O}_{4}$ nanoparticles, which could release more free iron to promote the formation of highly reactive oxygen species combined with electromagnetic fields, achieving remote modulation of redox state of Walker-256 carcinosarcoma tumor 

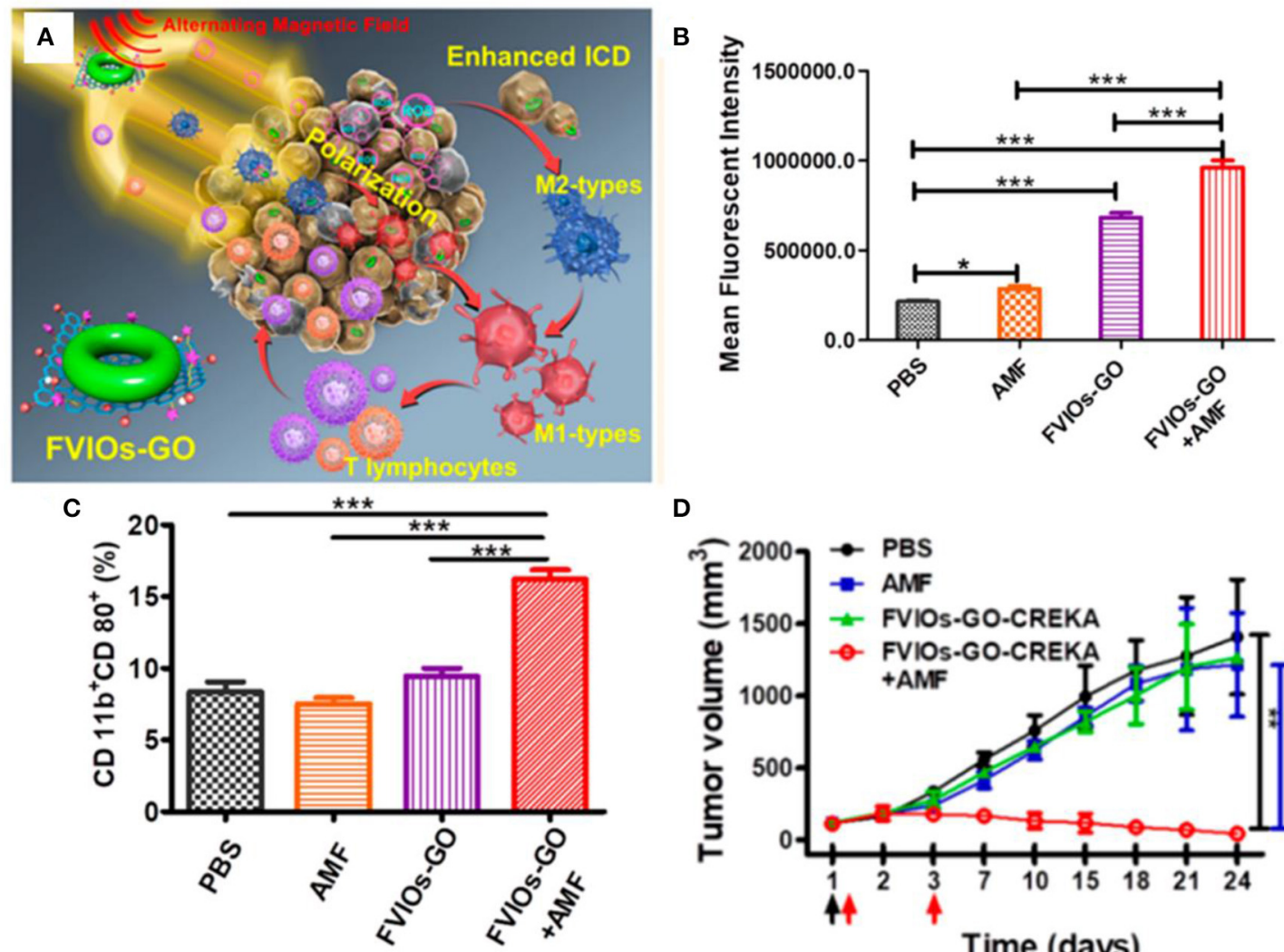

D

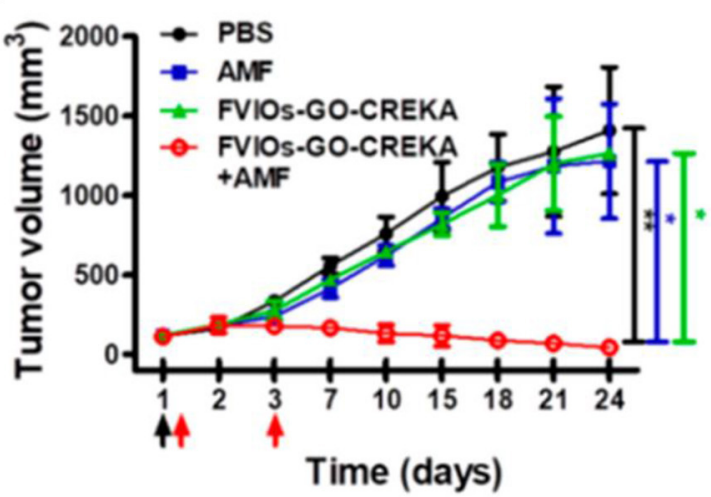

FIGURE 9 | (A) Schematic illustration for FVIOs-GO-mediated MTD by combination of a heating effect and ROS-related immunologic effect. (B) Quantification of ROS generation of $4 \mathrm{~T} 1$ breast cancer cells. (C) Quantification of M1 macrophages for treatments. (D) Tumor volume vs. days after treatments.

${ }^{\star} 0.01<P<0.05 ;{ }^{\star \star} 0.001<P<0.01 ;{ }^{* \star \star} P<0.001$. Reproduced, with permission, from Liu et al. (2020). Copyright 2020, American Chemical Society.

for cancer nanotherapy (Orel et al., 2018). Lin et al. synthesized magnetic hydroxyapatite nanoparticles by coprecipitation with the addition of $\mathrm{Fe}^{2+}$ (mHAP), which could increase intracellular ROS concentration to cause DNA damage of HepG2 cells with possible MKK3/MKK6 and ATF-2 of p38 MAPK inhibition under exposure to alternating magnetic field (Yang et al., 2018). Zhang et al. designed a magnetic hydrogel nanozyme utilizing PEGylated $\mathrm{Fe}_{3} \mathrm{O}_{4}$ nanoparticles and a-cyclodextrin, which could enhance tumor oxidative stress level by generating more ROS through promoted peroxidase-like enzymatic activity of $\mathrm{Fe}_{3} \mathrm{O}_{4}$ nanozyme at 42 hyperthermia induced by a non-invasive external alternating current magnetic field (Wu et al., 2019). Fan et al. demonstrated a biocompatible elaborate ferrimagnetic vortex-domain iron oxide nanoring and graphene oxide hybrid nanoparticle (FVIOs-GO-CREKA), which had high thermal conversion efficiency to significantly amplify the generation of ROS under an alternating magnetic field, promoting macrophage polarization to proinflammatory M1 phenotypes and elevating tumor-infiltrating $\mathrm{T}$ lymphocytes to provoke a strong immune response at a physiological tolerable temperature below 40 in a hypoxic tumor microenvironment (Figure 9) (Liu et al., 2020). Hilger et al. reported that the magnetic heating treatment could induce more production of ROS and alter messenger RNA (mRNA) expression of Ki-67, TOP2A, and TPX2, resulting in reducing tumor volumes superior to that of extrinsic heating (hot air) significantly (Ludwig et al., 2017). The effect of treatment under static magnetic field has also attracted the interest of researchers. Pazik et al. investigated the viability of canine mastocytoma tumor cells cultured with cobalt-manganese ferrite nanoparticles $\left(\mathrm{Co}_{0.2} \mathrm{Mn}_{0.8} \mathrm{Fe}_{2} \mathrm{O}_{4}\right)$ under $0.5 \mathrm{~T}$ static magnetic field (Marycz et al., 2017). The nanoparticles and magnetic field increase the temperature of tumor cells and the formation of reactive oxygen species, inducing apoptotic response.

Multifield coupling can often produce better synergistic therapeutic effects. Hassan et al. designed nanohybrid using nanoflower-like iron oxide and spiky copper sulfide shell (IONF@CuS), which could efficiently convert light and magnetic stimulation into heat and form concurrent reactive oxygen species upon laser irradiation for a tri-therapeutic strategy merging magnetic hyperthermia and photothermal and photodynamic therapy (Curcio et al., 2019). Fan et al. designed biocompatible $\mathrm{Fe}_{3} \mathrm{O}_{4}$-Pd Janus nanoparticles, which could enhance ROS generation due to the interface synergistic effect in producing hydroxyl radicals by $\mathrm{Fe}_{3} \mathrm{O}_{4}$ nanoparticle-based Fenton reaction and $\mathrm{Pd}$ nanosheet-based catalytic properties under external alternating magnetic field plus laser irradiation, exhibiting a high tumor-inhibition efficacy $[100 \%$ tumor inhibition rate at a dose of $6 \mathrm{mg} \mathrm{kg}^{-1}$ under alternating magnetic 


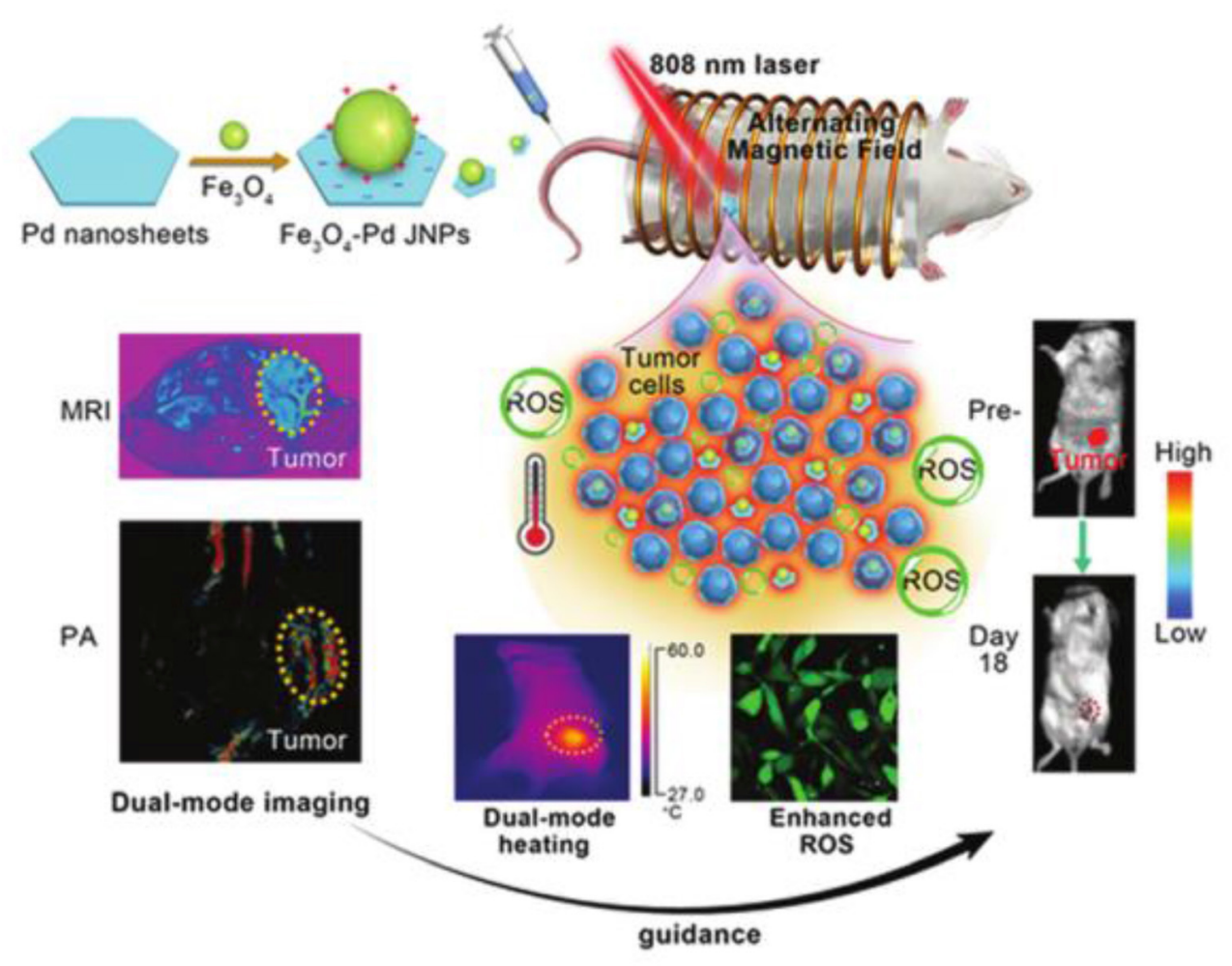

FIGURE 10 | A schematic illustration for $\mathrm{Fe}_{3} \mathrm{O}_{4}$-Pd JNPs enhanced ROS-mediated antineoplastic therapy. Reproduced, with permission, from Ma et al. (2019). Copyright 2019, Royal Society of Chemistry.

field (AMF) (300 kHz; $300 \mathrm{Oe})$ and laser $\left(808 \mathrm{~nm} ; 0.5 \mathrm{~W} \mathrm{~cm}^{-2}\right)$ ] toward 4T1 orthotopic breast tumor (Figure 10) (Ma et al., 2019). Sharma et al. developed manganese doped-iron oxide nanoclusters, which could trigger heat-induced enhancement of the Fenton reaction for the generation of $\bullet \mathrm{OH}$ under the dual application of magnetic hyperthermia and photothermal stimulation, resulting in a remarkable anticancer effect mediated by ROS-dependent apoptosis via the mitochondrial pathway (Gupta and Sharma, 2020).

\section{Cascade Reactions Increased ROS}

The rapid growth of the tumor tissues and the incomplete blood vessels lead to a hypoxia environment within solid tumors (Knowles and Harris, 2001). The concentration of intratumoral $\mathrm{H}_{2} \mathrm{O}_{2}$ is generally considered to be as low as $50-100 \mu M$, which is not high enough to generate an effective amount of hydroxyl radicals for a satisfactory cancer therapy (Chen et al., 2017b). Intratumoral injection of hydrogen peroxide is an effective method to increase the ROS-mediated tumor therapeutic effect (Zhang et al., 2013). However, this method has poor controllability and safety, causing damage to the surrounding healthy tissues. The cascade reactions have shown a good prospect in overcoming the tumor hypoxia and increasing the ROS production.

The most commonly used strategy is to generate more intratumoral hydrogen peroxide in situ through cascade reactions for the subsequent Fenton reaction. The $\beta$-lapachone was used earlier in such cascade reactions, which could undergo redox cycles to generate high $\mathrm{H}_{2} \mathrm{O}_{2}$ levels inside cancer cells. Gao et al. developed $\mathrm{pH}$-responsive superparamagnetic iron oxide nanoparticles (SPION micelles), which could selectively release iron ions in tumor acidic environment to react with $\mathrm{H}_{2} \mathrm{O}_{2}$ generated from $\beta$-lapachone to produce 10 -fold highly active hydroxyl radicals, displaying a synergistic efficacy for cancer treatment with ROS-generating anticancer drug (Huang et al., 2013). In another similar study, Chen et al. constructed a nanomedicine by encapsulating $\beta$-lapachone (La) and IONPs into the hydrophobic core of nanostructure formed by polyprodrug and polymer, which could be internalized by tumor cells and disintegrated in acidic environment to release La and iron ions (Wang et al., 2019b). The released La generated massive $\mathrm{H}_{2} \mathrm{O}_{2}$ through the catalysis of the nicotinamide adenine dinucleotide (phosphate) $[\mathrm{NAD}(\mathrm{P}) \mathrm{H}]$ : quinone oxidoreductase 1 (NQO1), which would further be converted to highly toxic $\bullet \mathrm{OH}$ by Fenton reaction with iron ions, resulting in improved antitumor activity. Ascorbic acid, a known antioxidant, can also be used to produce endogenous $\mathrm{H}_{2} \mathrm{O}_{2}$. Wang et al. synthesized $\mathrm{Fe}_{3} \mathrm{O}_{4} @ \mathrm{C}$ nanoparticles modified with folic acid $\left(\mathrm{Fe}_{3} \mathrm{O}_{4} @ \mathrm{C}-\mathrm{FA}\right)$, which could create hydroxyl radicals from $\mathrm{H}_{2} \mathrm{O}_{2}$ yielded by the exogenous ascorbic acid, inducing the selective killing of cancer cells owing to ROS accumulation in human prostate cancer PC-3 cells (An et al., 
2013). In a similar study, as low as $0.1 \mathrm{mM}$ exogenous vitamin $\mathrm{C}$ was catalyzed by iron oxide nanoparticle to generate $\mathrm{H}_{2} \mathrm{O}_{2}$ followed by ROS production in the form of hydroxyl/superoxide radicals, inducing effective tumor cell death (Pal and Jana, 2020). Cisplatin is also commonly used as cascade reaction trigger agent. Lin et al. constructed selfsacrificing iron oxide nanoparticles with cisplatin (IV) prodrug (FePt-NP2), which could release cisplatin and $\mathrm{Fe}^{2+} / \mathrm{Fe}^{3+}(\mathrm{Ma}$ et al., 2017). The released cisplatin could activate nicotinamide adenine dinucleotide phosphate (NADPH) oxidase to trigger oxygen to generate superoxide radical, which could be further dismutated by superoxide dismutase to form downstream $\mathrm{H}_{2} \mathrm{O}_{2}$. The generated $\mathrm{H}_{2} \mathrm{O}_{2}$ would be catalyzed by $\mathrm{Fe}^{2+} / \mathrm{Fe}^{3+}$ to the toxic hydroxyl radicals, causing ROS-mediated oxidative damages to lipids, proteins, and DNA and inducing tumor cell apoptosis. This strategy was also adopted by Chen et al. to design cisplatin-loaded $\mathrm{Fe}_{3} \mathrm{O}_{4} / \mathrm{Gd}_{2} \mathrm{O}_{3}$ hybrid nanoparticles with conjugation of lactoferrin and RGD dimer (FeGdHN@Pt@LF/RGD2), which could release cisplatin, Fe ${ }^{2+}$, and $\mathrm{Fe}^{3+}$ after endocytosis in the endosomes, leading to high inhibition efficacy on orthotopic brain tumors (Shen et al., 2018). Ni et al. synthesized FA/Pt+si-GPX4@IONPs for gene treatment of glioblastoma (Zhang et al., 2020b). The cascade reactions triggered by $\mathrm{Pt}$ laid the foundation for efficient ROS production to induce a combination of ferroptosis and apoptosis. Another cascade reaction strategy developed by Shi et al. reported a sequential catalytic nanomedicine using natural glucose oxidase and synthetic ultrasmall $\mathrm{Fe}_{3} \mathrm{O}_{4}$ nanoparticles

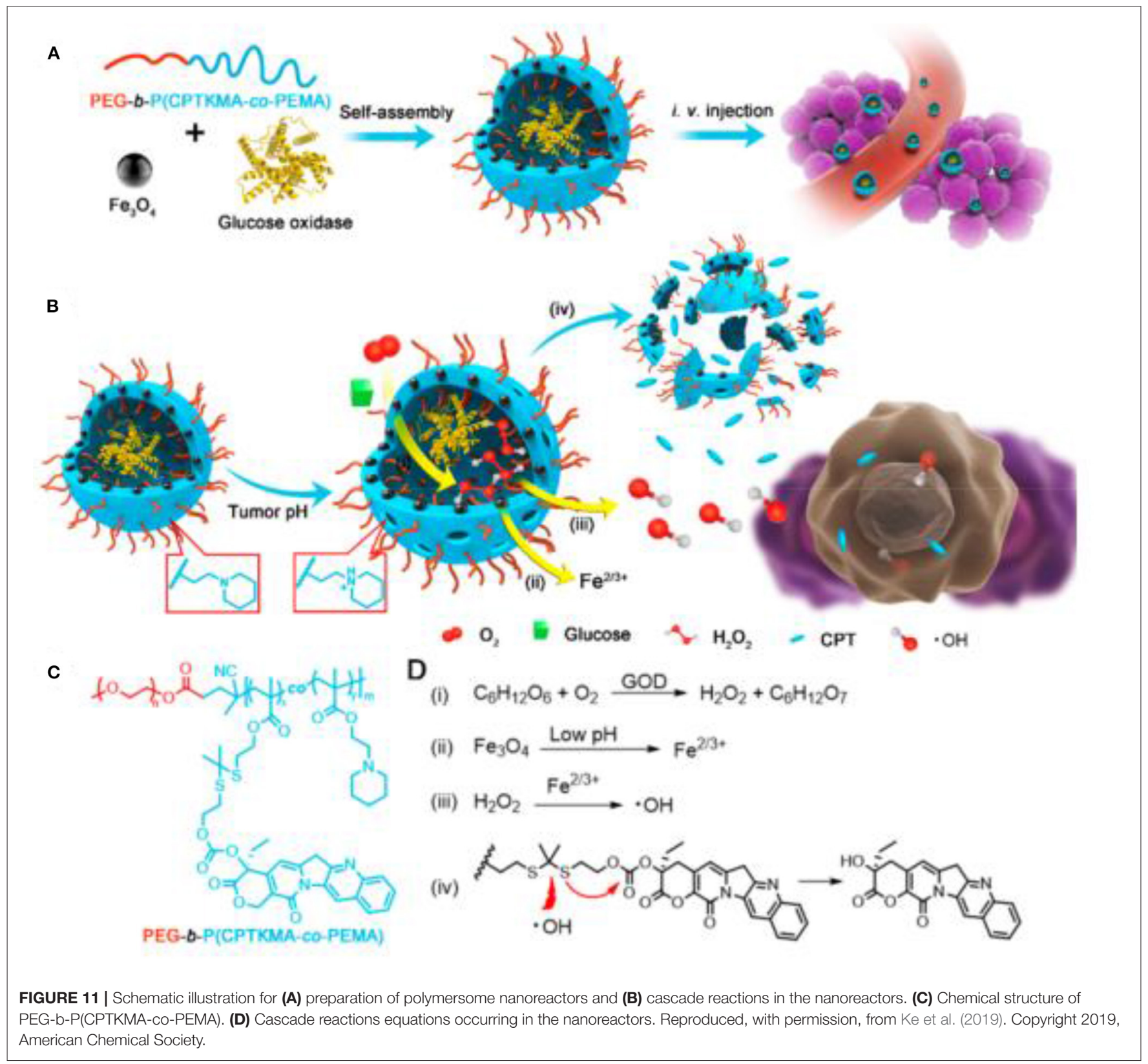


to integrate into the large mesopores of dendritic mesoporous silica nanoparticles (GFD NCs) (Huo et al., 2017). The glucose oxidase (GOD) released from nanocatalysts could deplete the glucose to produce considerable amounts of $\mathrm{H}_{2} \mathrm{O}_{2}$, which could be converted into highly toxic hydroxyl radical through Fenton-like reaction catalyzed by $\mathrm{Fe}_{3} \mathrm{O}_{4}$ nanoparticles to trigger the apoptosis and death of tumor cells. This strategy was further studied by Ge et al.. They engineered ultrasmall iron oxide nanoparticles (USIONs) and GOD-coloaded PEG-bP(CPTKMA-co-PEMA) polymersomes nanoreactors (Fe/G@RNRs), which could occur cascade reactions including glucose consumption to generate $\mathrm{H}_{2} \mathrm{O}_{2}$ by GOD, production of $\bullet \mathrm{OH}$ through Fenton reaction between $\mathrm{H}_{2} \mathrm{O}_{2}$ and iron ion released by USIONs, and $\cdot \mathrm{OH}$-triggered rapid release of polyprodrug for orchestrated cooperative cancer therapy including starving therapy, chemodynamic therapy, and chemotherapy (Figure 11) (Ke et al., 2019). Xu et al. developed glucose oxidase and polydopamine-functionalized iron oxide nanoparticles $\left(\mathrm{Fe}_{3} \mathrm{O}_{4} @ \mathrm{PDA} / \mathrm{GOx} \mathrm{NPs}\right)$, in which the enzymatic activity of
GOx was stably retained due to the excellent biocompatibility of polydopamine (Zhang et al., 2019). For cancer cells incubated with the $200 \mathrm{~nm}$ NPs, the $\bullet O H$ accumulation within the cells was about 2-fold higher than that with $20 \mathrm{~nm}$ NPs treatment, efficiently inducing the apoptosis of cancer cells. Peroxide can be employed as potent $\mathrm{H}_{2} \mathrm{O}_{2}$ supplier to sustain the ferrite nanoparticles-mediated Fenton reaction. Shi et al. constructed 2D multifunctional therapeutic nanoreactors by conjugating iron oxide nanoparticles and calcium peroxide onto niobium carbide $\left(\mathrm{Nb}_{2} \mathrm{C}-\mathrm{IO}-\mathrm{CaO}_{2}\right)$ (Gao et al., 2019). The $\mathrm{CaO}_{2}$ could react with $\mathrm{H}_{2} \mathrm{O}$ to produce $\mathrm{H}_{2} \mathrm{O}_{2}$ in the acidic tumor microenvironment, which was subsequently disproportionated into highly toxic - $\mathrm{OH}$ by the IO nanoparticles for inducing tumor cell death. With laser irradiation, graphene oxide can produce more reactive graphene radicals to enhance the ROS formation. Huang et al. developed a near-infrared absorbing nanoagent using graphene oxide loaded with iron hydroxide/oxide $\left(\mathrm{GO}-\mathrm{FeO}_{\mathrm{x}} \mathrm{H}\right)$ via one-step electrooxidation ( $\mathrm{He}$ et al., 2017). The electron transfer from $\mathrm{GO}$ to the $\mathrm{Fe}^{3+}$ of $\mathrm{FeO}_{\mathrm{x}} \mathrm{H}$ could promote

\section{A}

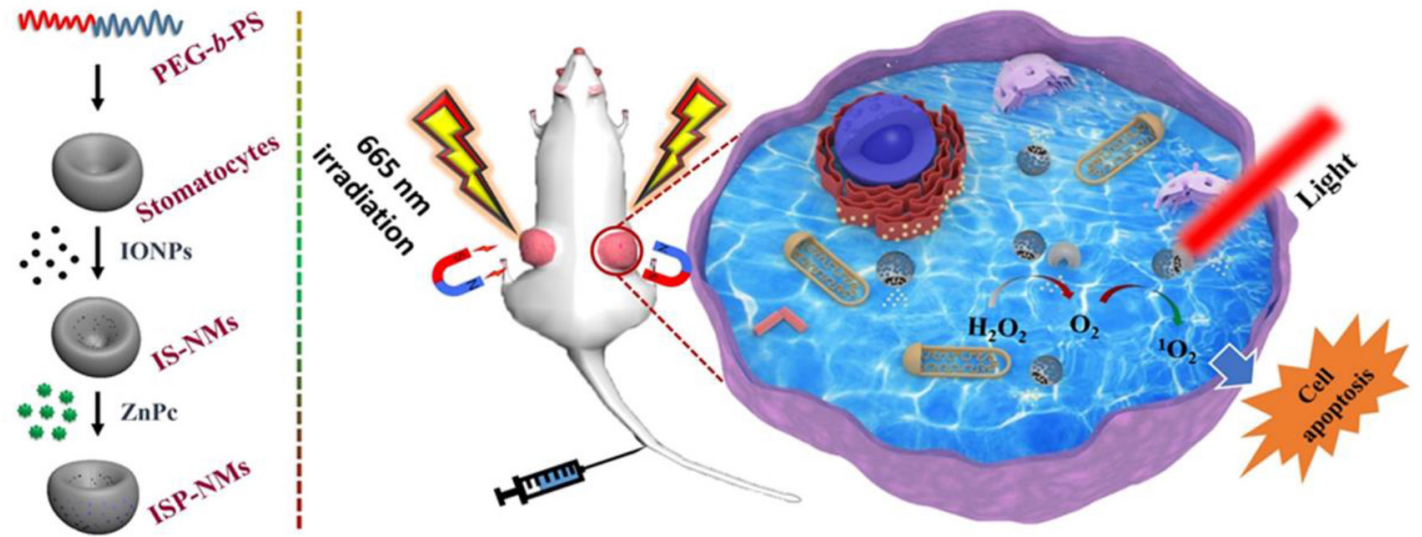

B

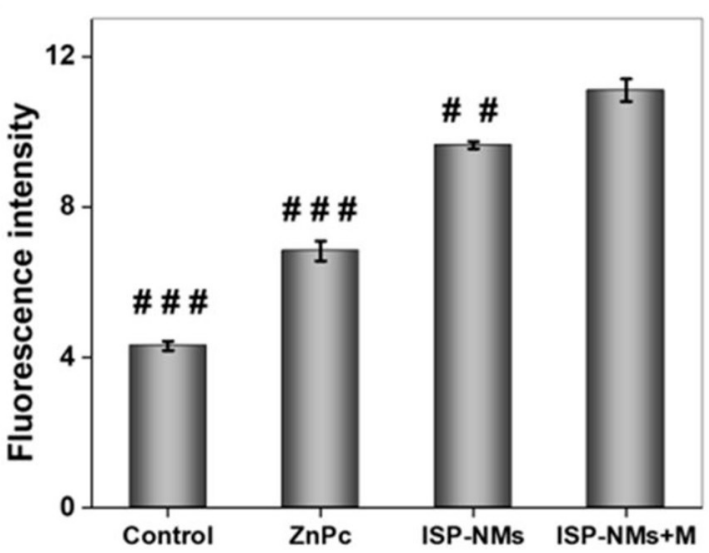

C

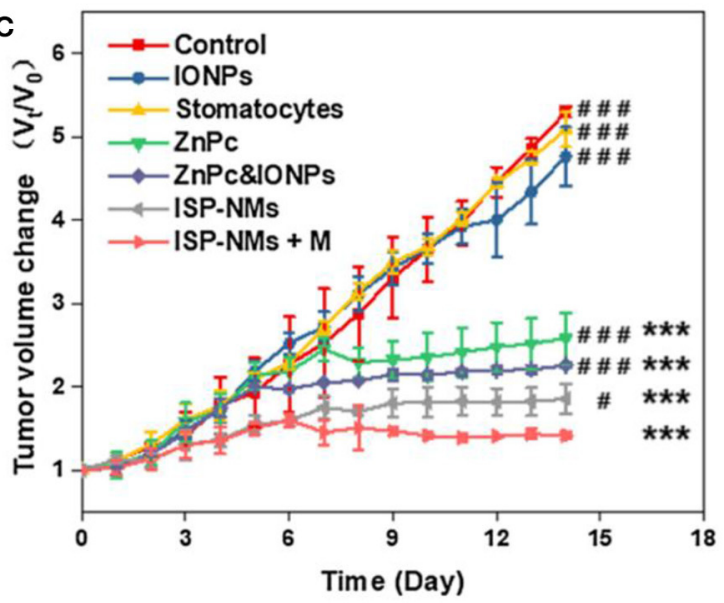

FIGURE 12 | (A) Schematic diagram of ISP-NMs and application for cancer treatment. (B) Fluorescent intensity of cancer cells after treatment. (C) Tumor volume changes during 14 days. ${ }^{*} P<0.05$. ${ }^{\star \star} P<0.01 .{ }^{\star \star *} P<0.001$ drugs treated groups versus one of control; $\# P<0.05$, $\# \# P<0.01$, \#\#\# $P<0.001$ other drugs treated groups versus the group of ISP-NMs+M. Reproduced, with permission, from Zhang et al. (2020a). Copyright 2020, Elsevier. 
A

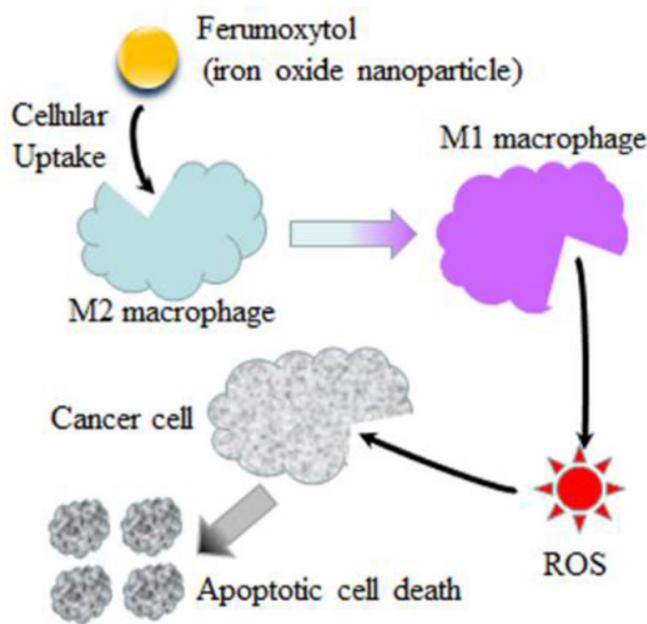

C

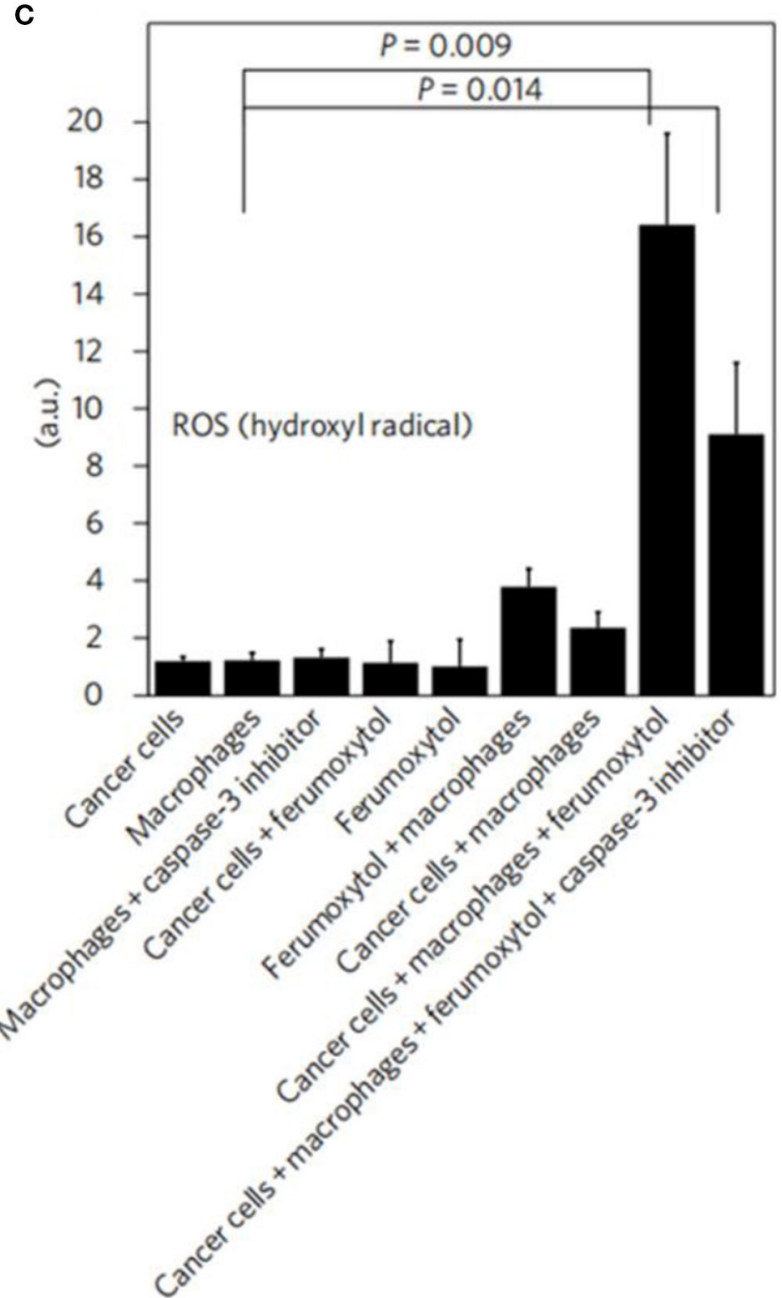

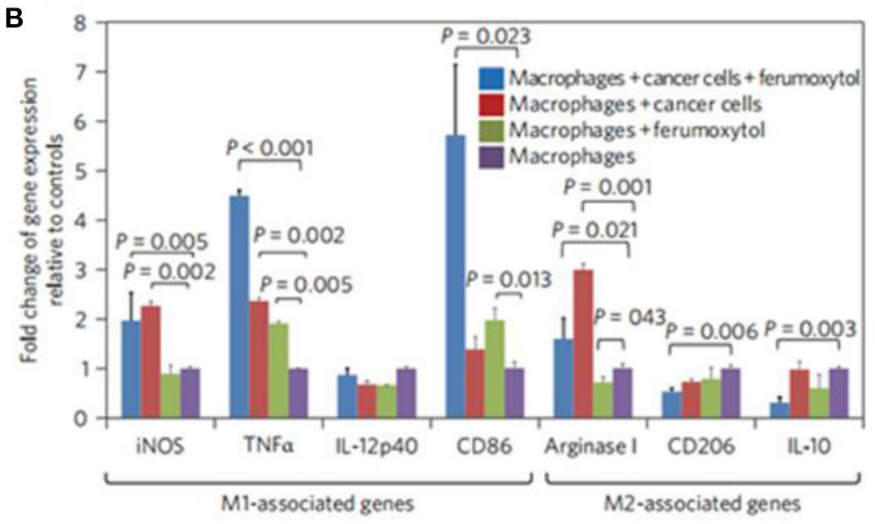

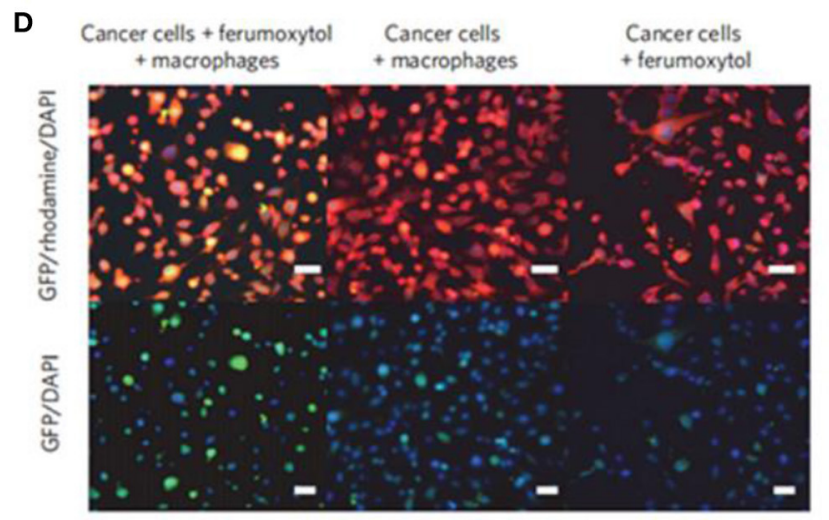

E
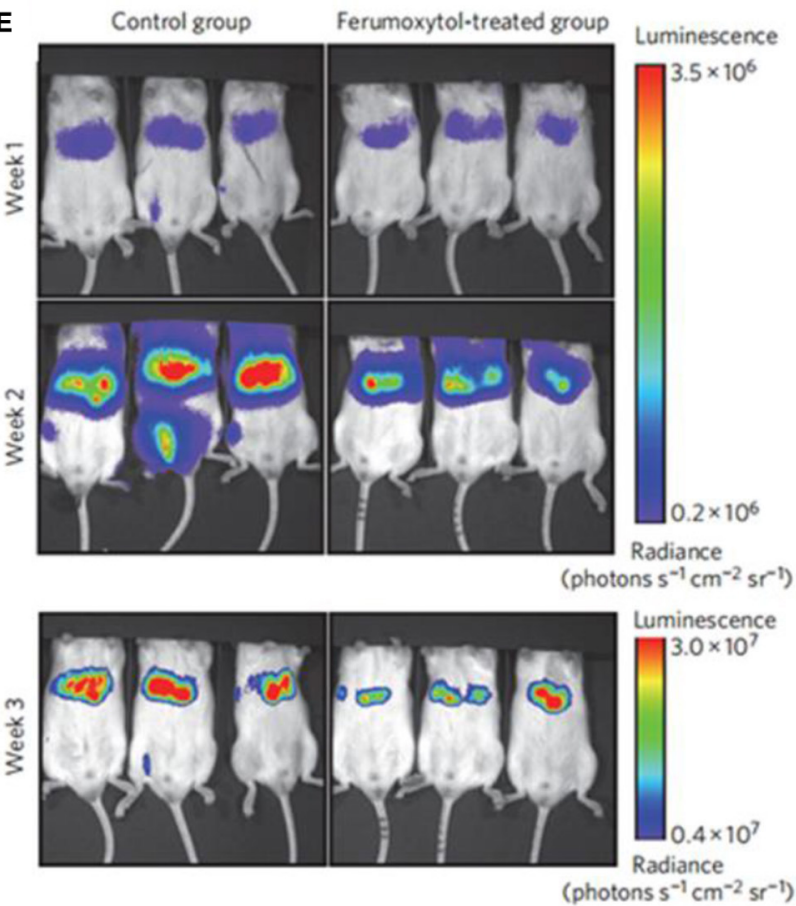

FIGURE 13 | (A) Schematic illustration of ferumoxytol-altered polarization of tumor-associated macrophages to release ROS, inducing cell death. (B) Signs of proinflammatory macrophage activation. (C) Quantitative measures of hydroxyl radical. (D) Coculture leads to increased caspase-3 expression of cancer cells. (E)

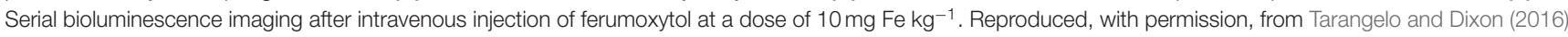
and Zanganeh et al. (2016). Copyright 2016, Macmillan Publishers Limited. 
TABLE 1 | Summary of current ferrite nanoparticles used for ROS-mediated cancer therapy.

\begin{tabular}{|c|c|c|c|}
\hline ROS production & Ferrite-based nanoplatform & Brief description & References \\
\hline \multirow[t]{26}{*}{ Intrinsic fenton reaction } & $\mathrm{Fe}_{3} \mathrm{O}_{4}(6,13 \mathrm{~nm})$ & Smaller size, higher enzyme activity & Zhang et al., 2013 \\
\hline & $\mathrm{Fe}_{3} \mathrm{O}_{4}(6,9$, and $14 \mathrm{~nm})$ & $\begin{array}{l}\text { Small size NPs destroy mitochondria, while } \\
\text { larger size destroy cytomembrane }\end{array}$ & Xie et al., 2016 \\
\hline & SPIONs $(7.3,15.1,30.0 \mathrm{~nm})$ & & Zhang et al., 2020c \\
\hline & $\mathrm{FeO}_{x}-\mathrm{MSNs}$ & pH responsive, delivered to acidic lysosomes & Fu et al., 2015 \\
\hline & $\begin{array}{l}\mathrm{Fe}_{3} \mathrm{O}_{4} \text { nanocluster, nanoflower, and } \\
\text { nanodiamond }\end{array}$ & $\begin{array}{l}\mathrm{Fe}_{3} \mathrm{O}_{4} \text { nanodiamonds induce the highest cell } \\
\text { killing effect }\end{array}$ & Fu et al., 2017 \\
\hline & $\mathrm{CuFe}_{2} \mathrm{O}_{4}$ & $\begin{array}{l}\text { Non-ferrous metal species regulate the ROS } \\
\text { production }\end{array}$ & Ahamed et al., 2016 \\
\hline & MB-CuFe NPs & & Kuo et al., 2020 \\
\hline & $\mathrm{SnFe}_{2} \mathrm{O}_{4}$ & & Lee et al., 2017 \\
\hline & Iridium oxide and iron oxide & & Shaikh et al., 2020 \\
\hline & $\mathrm{CuO}, \gamma \mathrm{Fe}_{2} \mathrm{O}_{3}, \mathrm{CuZnFe} \mathrm{O}_{3}$ & & Siddiqui et al., 2020 \\
\hline & $\mathrm{Fe}_{2} \mathrm{O}_{3} @ \mathrm{DMSA}, \mathrm{Fe}_{2} \mathrm{O}_{3} @ \mathrm{APTS}$ & DMSA-coating promotes uptake efficiency & Xie et al., 2020 \\
\hline & $\mathrm{Fe}_{3} \mathrm{O}_{4} / \mathrm{Fe} @ \mathrm{~F}-\mathrm{SiO}_{2} / \mathrm{PDA}$ & $\begin{array}{l}\text { Catalase-imprinted shell inhibits catalase } \\
\text { activity to elevate } \mathrm{H}_{2} \mathrm{O}_{2} \text { level }\end{array}$ & Chen et al., 2017a \\
\hline & mag. SLPs & $\begin{array}{l}\text { Targeting molecules, responsive molecules, } \\
\text { improved delivery efficiency and selectivity }\end{array}$ & Swietek et al., 2020 \\
\hline & Mito-PANPs & & Pandey et al., 2020 \\
\hline & $\mathrm{Fe}_{5} \mathrm{C}_{2} @ \mathrm{Fe}_{3} \mathrm{O}_{4}$ & Gradient core-shell structure, differential release & Yu et al., 2019 \\
\hline & PEGylated FePt- $\mathrm{Fe}_{3} \mathrm{O}_{4}+$ doxorubicin & $\begin{array}{l}\text { Combining ferrite nanoparticle and } \\
\text { chemotherapeutic drugs, chemical and } \\
\text { biological agents, etc. improves ROS-mediated } \\
\text { tumor therapy. }\end{array}$ & Sahu et al., 2015 \\
\hline & $\mathrm{H}_{2} \mathrm{O}_{2} / \mathrm{Fe}_{3} \mathrm{O}_{4}-\mathrm{PLGA}$ polymersome & & Li et al., 2016 \\
\hline & Nickel ferrite nanoparticles & & Ahamed et al., 2015 \\
\hline & Magnetite iron oxide nanoparticles & & Gokduman, 2019 \\
\hline & $\mathrm{Fe}_{3} \mathrm{O}_{4} @$ LEC-CUR-PLGA-MMS & & Ayyanaar et al., 2020 \\
\hline & $\mathrm{Fe}_{3} \mathrm{O}_{4} @ \mathrm{CPTMOS} / \mathrm{TP} \mathrm{NPS}$ & & Habibzadeh et al., 2020 \\
\hline & $\alpha-\mathrm{Fe}_{2} \mathrm{O}_{3}$ & & Ramalingam et al., 2020 \\
\hline & SPIONs & & Jahanbani et al., 2020 \\
\hline & SPIONs & $\begin{array}{l}\text { Mechanisms: mitochondrial electron transport } \\
\text { chain, antioxidant-related genes, } \\
\text { mTOR-Akt-p70S6 K and ATG7, etc. }\end{array}$ & He et al., 2016a \\
\hline & $9 \mathrm{~nm} \mathrm{Fe} \mathrm{O}_{4} \mathrm{NPs}$ & & Ye et al., 2020 \\
\hline & PEI-MNPs & & Man et al., 2020 \\
\hline \multirow{5}{*}{$\begin{array}{l}\text { External field enhanced } \\
\text { ROS }\end{array}$} & $\mathrm{NiFe}_{2} \mathrm{O}_{4} / \mathrm{C}$ & Enhanced by ultrasound & Gorgizadeh et al., 2019 \\
\hline & Citrate-coated SPIONs & $\begin{array}{l}\text { Increased ROS production under X-ray } \\
\text { irradiation, etc. }\end{array}$ & Klein et al., 2012 \\
\hline & $9-20 \mathrm{~nm}\left(\gamma-\mathrm{Fe}_{2} \mathrm{O}_{3}\right)_{1-\mathrm{x}}\left(\mathrm{Fe}_{3} \mathrm{O}_{4}\right)_{x}$ & & Klein et al., 2014 \\
\hline & Cetuximab-IONPs & & Bouras et al., 2015 \\
\hline & TAT- $-\mathrm{Fe}_{3} \mathrm{O}_{4}$ & & Hauser et al., 2016b \\
\hline
\end{tabular}


TABLE 1 | Continued

\section{ROS production}

\section{Ferrite-based nanoplatform}

PA-SAM functionalized $\mathrm{Fe}_{3} \mathrm{O}_{4}$ and $\mathrm{CoFe}_{2} \mathrm{O}_{4} \mathrm{MNPS}$

$\mathrm{Zn}^{2+}$-doped magnetic nanoparticles

Bacterial magnetic nanoparticles

IONPs-ICG-HA

$\gamma \mathrm{GDYO}-\mathrm{Fe}_{3} \mathrm{O}_{4}$-CREKA (TTIS)

$\mathrm{Pt} / \mathrm{Fe}_{3} \mathrm{O}_{4} @ \mathrm{SP}-\mathrm{PLGA}$

$\mathrm{FeTiO}_{3} @ \mathrm{Fe}_{2} \mathrm{O}_{3}$

TAT-IONP

Doxorubicin-loaded $\mathrm{Fe}_{3} \mathrm{O}_{4}$ nanoparticles

mHAP

Magnetic hydrogel nanozyme (MHZ)

FVIOs-GO-CREKA

Iron oxide magnetic nanoparticles

$\mathrm{Co}_{0.2} \mathrm{Mn}_{0.8} \mathrm{Fe}_{2} \mathrm{O}_{4}$

IONF@CUS

$\mathrm{Fe}_{3} \mathrm{O}_{4}-\mathrm{Pd}$

Manganese doped-iron oxide nanoclusters (MNCs)

Cascades increased ROS
SPION micelles

LaCIONPS

$\mathrm{Fe}_{3} \mathrm{O}_{4} @ \mathrm{C}-\mathrm{FA}$

Vitamin C-conjugated $\mathrm{Fe}_{3} \mathrm{O}_{4}$

FePt-NP2

FeGd-HN@Pt@LF/RGD2

FA/Pt+si-GPX4@|ONPs

GFD NCs

Fe/G@R-NRs

$\mathrm{Fe}_{3} \mathrm{O}_{4} @ P D A / G O x$ NPs

$\mathrm{Nb}_{2} \mathrm{C}-\mathrm{IO}-\mathrm{CaO}_{2}$

$\mathrm{GO}-\mathrm{FeO}_{x} \mathrm{H}$

MFMSNs-Ce6

UCMnFe-PS-PEG

$\mathrm{MnFe}_{2} \mathrm{O}_{4} @ M O F-P E G$

Copper ferrite nanospheres (CFNs)

HP-HIONs

ISP-NMs

Ferumoxytol nanoparticles

$\mathrm{Fe}_{3} \mathrm{O}_{4}$-Au JNPs self-assembled vesicles
Brief Description

Improved catalytic activity under NIR
photothermal energy

Nanoplatform depolymerizes under NIR

Photothermal energy

$650 \mathrm{~nm}$ laser irradiation formed photoexcited electron-hole

Improved catalytic activity under AMF magnetic heat

Magnetic heating superior to extrinsic hot air heating

0.5 T static magnetic field

Synergistic effect of multi-field coupling (AMF and laser irradiation)

$\beta$-lapachone increases $\mathrm{H}_{2} \mathrm{O}_{2}$

Ascorbic acid increases $\mathrm{H}_{2} \mathrm{O}_{2}$

Cisplatin activates NADPH oxidase to generate $\mathrm{H}_{2} \mathrm{O}_{2}$

Glucose oxidase consumes glucose to generate $\mathrm{H}_{2} \mathrm{O}_{2}$

$\mathrm{CaO}_{2}$ as $\mathrm{H}_{2} \mathrm{O}_{2}$ supplier

Graphene oxide produces ROS under laser irradiation.

Ferrite nanoparticles catalyze decomposition of $\mathrm{H}_{2} \mathrm{O}_{2}$ to $\mathrm{O}_{2}$ to overcome tumor hypoxia, improving ROS-mediated cancer therapy.

Ferumoxytol acted on tumor-associated macrophages to adapt an antitumor "M1" phenotype, enhancing macrophage ROS production.

poly(lipid hydroperoxide) reacts with released $\mathrm{Fe}^{2+}$ to generate ROS

\section{References}

Klein et al., 2018

Qi et al., 2016

Chen et al., 2016

Wang et al., 2019a

Min et al., 2020

You et al., 2019

Ou et al., 2020

Hauser et al., 2016a

Orel et al., 2018

Yang et al., 2018

Wu et al., 2019

Liu et al., 2020

Ludwig et al., 2017

Marycz et al., 2017

Curcio et al., 2019

Ma et al., 2019

Gupta and Sharma, 2020

Huang et al., 2013

Wang et al., 2019b

An et al., 2013

Pal and Jana, 2020

Ma et al., 2017

Shen et al., 2018

Zhang et al., 2020b

Huo et al., 2017

Ke et al., 2019

Zhang et al., 2019

Gao et al., 2019

He et al., 2017

Kim et al., 2017

Ding et al., 2019

Yin et al., 2019

Liu et al., 2018

Zhang et al., 2020d

Zhang et al., 2020a

Zanganeh et al., 2016

Song et al., 2019 
the reaction with $\mathrm{O}_{2}$ to generate superoxide anion radicals under NIR light irradiation, which would be converted into $\mathrm{H}_{2} \mathrm{O}_{2}$ through disproportionation reaction. The generated $\mathrm{H}_{2} \mathrm{O}_{2}$ then underwent a reaction with $\mathrm{Fe}^{2+}$ of $\mathrm{FeO}_{\mathrm{x}} \mathrm{H}$ to produce amplified hydroxyl radicals, triggering near-infrared activated ROS-mediated photodynamic therapy.

Ferrite nanoparticles are also used to catalyze the production of molecular oxygen to overcome tumor hypoxia, improving the ROS-mediated tumor therapeutic effect. Hyeon et al. designed manganese ferrite nanoparticle anchored mesoporous silica nanoparticles loaded with molecule chlorin e6 (MFMSNsCe6) (Kim et al., 2017). The manganese ferrite could catalyze decomposition of $\mathrm{H}_{2} \mathrm{O}_{2}$ to evolve $\mathrm{O}_{2}$, which could be further converted to singlet oxygen by photosensitizer Ce6, improving photodynamic therapeutic outcomes for hypoxic tumor. Some similar studies were carried out by other researchers. Lin et al. prepared photosensitizer-loaded and PEG-modified $\mathrm{MnFe}_{2} \mathrm{O}_{4}$-decorated large-pore mesoporous silica-coated $\beta$ $\mathrm{NaYF}_{4}: 20 \% \mathrm{Yb}, 2 \% \mathrm{Er} @ \beta-\mathrm{NaYF}_{4}$ upconversion nanoparticles (UCMnFe-PS-PEG) as NIR light-mediated and $\mathrm{O}_{2}$ selfsufficient photodynamic therapy (PDT) agents (Ding et al., 2019). The sub-10 nm $\mathrm{MnFe}_{2} \mathrm{O}_{4}$ nanoparticles not only provided magnetic guidance to the tumor but also worked as a Fenton catalyst to generate $\mathrm{O}_{2}$ in situ to overcome tumor hypoxia. The tumor growth was greatly inhibited, and some of the tumors even disappeared after 16 days of treatment. A biocompatible nanoplatform [ $\mathrm{MnFe}_{2} \mathrm{O}_{4} @$ metalorganic framework (MOF)] developed by Zhang et al. using a coating of porphyrin-based MOF as the photosensitizer and manganese ferrite nanoparticle $\left(\mathrm{MnFe}_{2} \mathrm{O}_{4}\right)$ as the enzyme can not only catalyze $\mathrm{H}_{2} \mathrm{O}_{2}$ to produce $\mathrm{O}_{2}$ to overcome the tumor hypoxia but also consume glutathione, achieving better therapeutic efficacy (Yin et al., 2019). The tumor growth was considerably suppressed after mice were treated with $\mathrm{MnFe}_{2} \mathrm{O}_{4} @ M O F-P E G$ (i.v. injection of $200 \mu \mathrm{l}, 6.25 \mathrm{mg}$ $\left.\mathrm{kg}^{-1} \mathrm{TCPP}\right)$ and laser irradiation $\left(0.8 \mathrm{~W} \mathrm{~cm} \mathrm{~cm}^{-2}, 8 \mathrm{~min}\right.$, $24 \mathrm{~h}$ post-i.v. injection). Zhang et al. showed "all in one" theranostic agents copper ferrite nanospheres (CFNs), in which the coupling between $\mathrm{Fe}^{2+} / \mathrm{Fe}^{3+}$ and $\mathrm{Cu}^{+} / \mathrm{Cu}^{2+}$ redox pairs could produce more $\bullet \mathrm{OH}$ and $\mathrm{O}_{2}$ through Fenton reactions under 650-nm laser illumination (Liu et al., 2018). The produced $\mathrm{O}_{2}$ could be further converted into $\mathrm{O}_{2}^{-}$by photogenerated electron/hole pair for synergistic tumor ablation of photoenhanced chemodynamic therapy/photodynamic therapy/photothermal therapy. Lin et al. synthesized a novel nanoplatform composed of hollow iron oxide nanoparticles and hematoporphyrin sonosensitizers (HP-HIONs) (Zhang et al., 2020d). The HIONs possessed nanozyme activity for catalyzing decomposition of hydrogen peroxide to produce $\mathrm{O}_{2}$, which could be further converted to ROS by sonodynamic therapy for efficient cancer cell apoptosis. Wei et al. synthesized iron oxide nanoparticles-loaded stomatocytes@ZnPc nanomotors (ISP-NMs), in which IONPs catalyzed decomposition of endogenous $\mathrm{H}_{2} \mathrm{O}_{2}$ to generate $\mathrm{O}_{2}$ as propelling force to expand the distribution of $\mathrm{ZnPc}$ (Zhang et al., 2020a). The generated $\mathrm{O}_{2}$ was supplied to produce more ROS $\left({ }^{1} \mathrm{O}_{2}\right)$, enhancing PDT performance (Figure 12).
Some other strategies have also been developed to increase ROS generation. Daldrup-Link et al. coincubated adenocarcinoma with iron oxide nanoparticle compound ferumoxytol and macrophages (Zanganeh et al., 2016). Ferumoxytol nanoparticles increased presence of proinflammatory M1 macrophages in the tumor to enhance the production of hydrogen peroxide and hydroxyl radical for macrophage-modulating cancer immunotherapies (Figure 13). Chen et al. constructed double-layered vesicles with $\mathrm{Fe}_{3} \mathrm{O}_{4}$ face-to-face localized in the inner side and $\mathrm{Au}$ extended to the outer side by self-assembly of iron oxide-gold Janus nanoparticles $\left(\mathrm{Fe}_{3} \mathrm{O}_{4}\right.$-Au JNPs) using hydrophilic poly(ethylene glycol)-grafted $\mathrm{Au}$ and poly(lipid hydroperoxide)-co-poly(4vinyl pyrene)-coated $\mathrm{Fe}_{3} \mathrm{O}_{4}$. In the acidic tumor environment, the vesicles disassembled into single JNPs, allowing $\mathrm{Fe}_{3} \mathrm{O}_{4}$ to react with $\mathrm{H}^{+}$to release $\mathrm{Fe}^{2+}$. The released $\mathrm{Fe}^{2+}$ further reacted with poly(lipid hydroperoxide) to generate reactive oxygen species $\left({ }^{1} \mathrm{O}_{2}\right)$ and increase intracellular oxidative stress for better inhibition of tumor growth (Song et al., 2019).

\section{CONCLUSION AND FUTURE OUTLOOK}

In the past nearly 10 years, ROS-mediated cancer therapy using ferrite nanoparticles has been rapidly developed, and researchers have published a large number of related publications (summarized in Table 1). This review was carried on the classification and summarization of the application of ferrite nanoparticles in ROS-mediated cancer therapy. Based on the analysis of the current literature, it can be seen that various modification strategies for the ROS-mediated cancer therapies based on ferrite nanoparticles are producing more and more successful results, especially in combination with drugs, biological and chemical agents, and/or co-exposure of other energy fields such as X-rays, lasers, and alternating magnetic fields, becoming potential effective tumor therapy strategies. However, to date, only iron oxide nanoparticles have been approved for the magnetic response diagnosis and the magnetic hyperthermia tumor therapy (Park et al., 2017; Shi et al., 2017). Few clinical trials have been reported for any tumor therapy based on ferrite nanoparticle-induced ROS (Liang et al., 2020). The ferrite nanoparticle-induced ROS can kill the cancer cell and also can trigger the toxic effect on the normal tissues and vasculature. Therefore, in order to solve this dilemma, on the one hand, the high-performance ferrite nanoparticles should be developed to produce much more ROS so that the dosage of the particles can be reduced. On the other hand, the smart (stimulusresponsive) ferrite nanoparticles should be designed to produce more controllable ROS in tumor tissue and little to no ROS outside tumor tissue.

Having achieved the excellent performance of ROS-mediated cancer therapy based on ferrite nanoparticles on small animal model, there are still many important challenges before clinical application. First, further studies on the development of strategies for controllable synthesis of ferrite nanoparticles in large scale are needed to satisfy the requirement for clinical 
translation and commercialization. Second, the biosafety should be fully investigated on large animals, as most of the current ferrite nanoparticles biosafety evaluation in vivo is based on small animals, and the biosafety of the nanoparticles remains largely unexplored in large animals and even in human models. It is appealing to combine efforts from the researchers in the fields of oncology, biochemistry, nanotechnology, medicine, and materials to shed light on the future of ROS-mediated cancer therapy based on ferrite nanoparticles.

\section{REFERENCES}

Ahamed, M., Akhtar, M. J., Alhadlaq, H. A., and Alshamsan, A. (2016). Copper ferrite nanoparticle-induced cytotoxicity and oxidative stress in human breast cancer MCF-7 cells. Colloids Surf. B-Biointerfaces 142, 46-54. doi: 10.1016/j.colsurfb.2016.02.043

Ahamed, M., Akhtar, M. J., Alhadlaq, H. A., Khan, M. A. M., and Alrokayan, S. A. (2015). Comparative cytotoxic response of nickel ferrite nanoparticles in human liver HepG2 and breast MFC-7 cancer cells. Chemosphere 135, 278-288. doi: 10.1016/j.chemosphere.2015.03.079

Ahamed, M., Alhadlaq, H. A., Khan, M. A. M., and Akhtar, M. J. (2013). Selective killing of cancer cells by iron oxide nanoparticles mediated through reactive oxygen species via p53 pathway. J. Nanopart. Res. 15:1225. doi: 10.1007/s11051-012-1225-6

An, Q., Sun, C., Li, D., Xu, K., Guo, J., and Wang, C. (2013). Peroxidase-like activity of $\mathrm{Fe}_{3} \mathrm{O}_{4} @$ Carbon nanoparticles enhances ascorbic acid-induced oxidative stress and selective damage to PC-3 prostate cancer cells. ACS Appl. Mater. Interfaces 5, 13248-13257. doi: 10.1021/am4042367

Ayyanaar, S., Kesavan, M. P., Balachandran, C., Rasala, S., Rameshkumar, P., Aoki, S., et al. (2020). Iron oxide nanoparticle core-shell magnetic microspheres: applications toward targeted drug delivery. Nanomed. Nanotechnol. Biol. Med. 24:102134. doi: 10.1016/j.nano.2019.102134

Barton, M. B., Jacob, S., Shafiq, J., Wong, K., Thompson, S. R., Hanna, T. P., et al. (2014). Estimating the demand for radiotherapy from the evidence: a review of changes from 2003 to 2012. Radiother. Oncol. 112, 140-144. doi: 10.1016/j.radonc.2014.03.024

Birben, E., Sahiner, U. M., Sackesen, C., Erzurum, S., and Kalayci, O. (2012). Oxidative stress and antioxidant defense. World Allergy Organ. J. 5, 9-19. doi: 10.1097/WOX.0b013e3182439613

Bokare, A. D., and Choi, W. (2014). Review of iron-free Fenton-like systems for activating $\mathrm{H}_{2} \mathrm{O}_{2}$ in advanced oxidation processes. J. Hazard. Mater. 275, 121-135. doi: 10.1016/j.jhazmat.2014.04.054

Bouras, A., Kaluzova, M., and Hadjipanayis, C. G. (2015). Radiosensitivity enhancement of radioresistant glioblastoma by epidermal growth factor receptor antibody-conjugated iron-oxide nanoparticles. J. Neurooncol. 124, 13-22. doi: 10.1007/s11060-015-1807-0

Bray, F., Ferlay, J., Soerjomataram, I., Siegel, R. L., Torre, L. A., and Jemal, A. (2018). Global cancer statistics 2018: GLOBOCAN estimates of incidence and mortality worldwide for 36 cancers in 185 countries. CA Cancer J. Clin. 68, 394-424. doi: 10.3322/caac. 21492

Chen, C., Wang, S., Li, L., Wang, P., Chen, C., Sun, Z., et al. (2016). Bacterial magnetic nanoparticles for photothermal therapy of cancer under the guidance of MRI. Biomaterials 104, 352-360. doi: 10.1016/j.biomaterials.2016.07.030

Chen, J., Lei, S., Zeng, K., Wang, M., Asif, A., and Ge, X. (2017a). Catalaseimprinted $\mathrm{Fe}_{3} \mathrm{O}_{4} / \mathrm{Fe} @$ fibrous $\mathrm{SiO}_{2}$ /polydopamine nanoparticles: An integrated nanoplatform of magnetic targeting, magnetic resonance imaging, and dual-mode cancer therapy. Nano Res. 10, 2351-2363. doi: $10.1007 / \mathrm{s} 12274-017-1431-8$

Chen, Q., Liang, C., Sun, X., Chen, J., Yang, Z., Zhao, H., et al. (2017b). $\mathrm{H}_{2} \mathrm{O}_{2}$ responsive liposomal nanoprobe for photoacoustic inflammation imaging and tumor theranostics via in vivo chromogenic assay. Proc. Natl. Acad. Sci. U.S.A. 114, 5343-5348. doi: 10.1073/pnas.1701976114

\section{AUTHOR CONTRIBUTIONS}

SY, SZ, and MZ wrote the manuscript. SY and HZ revised the manuscript. HF provided useful suggestions. All authors contributed to the article and approved the submitted version.

\section{FUNDING}

This work was supported by National Natural Science Foundation of China (No. 81901908).

Chen, Z., Yin, J.-J., Zhou, Y.-T., Zhang, Y., Song, L., Song, M., et al. (2012). Dual enzyme-like activities of iron oxide nanoparticles and their implication for diminishing cytotoxicity. ACS Nano 6, 4001-4012. doi: 10.1021/nn300291r

Curcio, A., Silva, A. K. A., Cabana, S., Espinosa, A., Baptiste, B., Menguy, N., et al. (2019). Iron oxide nanoflowers @ CuS hybrids for cancer tri-therapy: interplay of photothermal therapy, magnetic hyperthermia and photodynamic therapy. Theranostics 9, 1288-1302. doi: 10.7150/thno.30238

Ding, B., Shao, S., Xiao, H., Sun, C., Cai, X., Jiang, F., et al. (2019). $\mathrm{MnFe}_{2} \mathrm{O}_{4}$ decorated large-pore mesoporous silica-coated upconversion nanoparticles for near-infrared light-induced and $\mathrm{O}_{2}$ self-sufficient photodynamic therapy. Nanoscale 11, 14654-14667. doi: 10.1039/c9nr04858h

Dolmans, D., Fukumura, D., and Jain, R. K. (2003). Photodynamic therapy for cancer. Nat. Rev. Cancer 3, 380-387. doi: 10.1038/nrc1071

Dong, L. M., Ye, C., Zheng, L. L., Gao, Z. F., and Xia, F. (2020). Twodimensional metal carbides and nitrides (MXenes): preparation, property, and applications in cancer therapy. Nanophotonics 9, 2125-2145. doi: 10.1515/nanoph-2019-0550

Feng, W., Wang, R., Zhou, Y., Ding, L., Gao, X., Zhou, B., et al. (2019). Ultrathin molybdenum carbide MXene with fast biodegradability for highly efficient theory-oriented photonic tumor hyperthermia. Adv. Funct. Mater. 29:1901942. doi: 10.1002/adfm.201901942

Forman, H. J., Maiorino, M., and Ursini, F. (2010). Signaling functions of reactive oxygen species. Biochemistry 49, 835-842. doi: 10.1021/bi9020378

Fu, J., Shao, Y., Wang, L., and Zhu, Y. (2015). Lysosome-controlled efficient ROS overproduction against cancer cells with a high $\mathrm{pH}$-responsive catalytic nanosystem. Nanoscale 7, 7275-7283. doi: 10.1039/c5nr00706b

Fu, S., Wang, S., Zhang, X., Qi, A., Liu, Z., Yu, X., et al. (2017). Structural effect of $\mathrm{Fe}_{3} \mathrm{O}_{4}$ nanoparticles on peroxidase-like activity for cancer therapy. Colloids Surf. B-Biointerfaces 154, 239-245. doi: 10.1016/j.colsurfb.2017.03.038

Gao, L., Zhuang, J., Nie, L., Zhang, J., Zhang, Y., Gu, N., et al. (2007). Intrinsic peroxidase-like activity of ferromagnetic nanoparticles. Nat. Nanotechnol. 2, 577-583. doi: 10.1038/nnano.2007.260

Gao, S., Lu, X., Zhu, P., Lin, H., Yu, L., Yao, H., et al. (2019). Self-evolved hydrogen peroxide boosts photothermal-promoted tumor-specific nanocatalytic therapy. J. Mater. Chem. B 7, 3599-3609. doi: 10.1039/c9tb00525k

Gokduman, K. (2019). Sensitization of cisplatin-resistant ovarian cancer cells by magnetite iron oxide nanoparticles: an in vitro study. Nanomedicine 14, 3177-3191. doi: 10.2217/nnm-2019-0126

Gorgizadeh, M., Azarpira, N., Lotfi, M., Daneshvar, F., Salehi, F., and Sattarahmady, N. (2019). Sonodynamic cancer therapy by a nickel ferrite/carbon nanocomposite on melanoma tumor: in vitro and in vivo studies. Photodiag. Photodyn. Ther. 27, 27-33. doi: 10.1016/j.pdpdt.2019. 05.023

Gupta, R., and Sharma, D. (2020). Manganese-doped magnetic nanoclusters for hyperthermia and photothermal glioblastoma therapy. Acs Appl. Nano Mater. 3, 2026-2037. doi: 10.1021/acsanm.0c00121

Habibzadeh, S. Z., Salehzadeh, A., Moradi-Shoeili, Z., and Shandiz, S. A. S. (2020). A novel bioactive nanoparticle synthesized by conjugation of 3-chloropropyl trimethoxy silane functionalized $\mathrm{Fe}_{3} \mathrm{O}_{4}$ and 1-((3-(4-chlorophenyl)-1-phenyl1H-pyrazol-4-yl)methylene)-2-(4-phenylth iazol-2-yl) hydrazine: assessment on anti-cancer against gastric AGS cancer cells. Mol. Biol. Rep. 47, 1637-1647. doi: 10.1007/s11033-020-05251-7 
Hauser, A. K., Anderson, K. W., and Hilt, J. Z. (2016a). Peptide conjugated magnetic nanoparticles for magnetically mediated energy delivery to lung cancer cells. Nanomedicine 11, 1769-1785. doi: 10.2217/nnm-2016-0050

Hauser, A. K., Mitov, M. I., Daley, E. F., McGarry, R. C., Anderson, K. W., and Hilt, J. Z. (2016b). Targeted iron oxide nanoparticles for the enhancement of radiation therapy. Biomaterials 105, 127-135. doi: 10.1016/j.biomaterials.2016.07.032

He, C., Jiang, S., Jin, H., Chen, S., Lin, G., Yao, H., et al. (2016a). Mitochondrial electron transport chain identified as a novel molecular target of SPIO nanoparticles mediated cancer-specific cytotoxicity. Biomaterials 83, 102-114. doi: 10.1016/j.biomaterials.2016.01.010

He, G., He, G., Zhou, R., Pi, Z., Zhu, T., Jiang, L., et al. (2016b). Enhancement of cisplatin-induced colon cancer cells apoptosis by shikonin, a natural inducer of ROS in vitro and in vivo. Biochem. Biophys. Res. Commun. 469, 1075-1082. doi: 10.1016/j.bbrc.2015.12.100

He, W., Zhou, Y.-T., Wamer, W. G., Boudreau, M. D., and Yin, J.-J. (2012). Mechanisms of the $\mathrm{pH}$ dependent generation of hydroxyl radicals and oxygen induced by $\mathrm{Ag}$ nanoparticles. Biomaterials 33, 7547-7555. doi: 10.1016/j.biomaterials.2012.06.076

He, Y., del Valle, A., Qian, Y., and Huang, Y.-F. (2017). Near infrared lightmediated enhancement of reactive oxygen species generation through electron transfer from graphene oxide to iron hydroxide/oxide. Nanoscale 9, 1559-1566. doi: $10.1039 / \mathrm{c} 6$ nr $08784 \mathrm{a}$

High, K. A., and Roncarolo, M. G. (2019). Gene therapy. N. Engl. J. Med. 381, 455-464. doi: 10.1056/NEJMra1706910

Huang, G., Chen, H., Dong, Y., Luo, X., Yu, H., Moore, Z., et al. (2013). Superparamagnetic iron oxide nanoparticles: amplifying ROS stress to improve anticancer drug efficacy. Theranostics 3, 116-126. doi: 10.7150/thno.5411

Huo, M., Wang, L., Chen, Y., and Shi, J. (2017). Tumor-selective catalytic nanomedicine by nanocatalyst delivery. Nat. Commun. 8:357. doi: 10.1038/s41467-017-00424-8

Jahanbani, J., Ghotbi, M., Shahsavari, F., Seydi, E., Rahimi, S., and Pourahmad, J. (2020). Selective anchoranticancer activity of superparamagnetic iron oxide nanoparticles (SPIONs) against oral tongue cancer using in vitro methods: the key role of oxidative stress on cancerous mitochondria. J. Biochem. Mol. Toxicol. 34:e22557. doi: 10.1002/jbt.22557

Johannsen, M., Thiesen, B., Wust, P., and Jordan, A. (2010). Magnetic nanoparticle hyperthermia for prostate cancer. Int. J. Hyperthermia 26, 790-795. doi: $10.3109 / 02656731003745740$

Kankala, R. K., Tsai, P.-Y., Kuthati, Y., Wei, P.-R., Liu, C.-L., and Lee, C.H. (2017). Overcoming multidrug resistance through co-delivery of ROSgenerating nano-machinery in cancer therapeutics. J. Mater. Chem. B 5, 1507-1517. doi: 10.1039/c6tb03146c

Ke, W., Li, J., Mohammed, F., Wang, Y., Tou, K., Liu, X., et al. (2019). Therapeutic polymersome nanoreactors with tumor-specific activable cascade reactions for cooperative cancer therapy. ACS Nano 13, 2357-2369. doi: 10.1021 /acsnano.8b09082

Kim, J., Cho, H. R., Jeon, H., Kim, D., Song, C., Lee, N., et al. (2017). Continuous $\mathrm{O}_{2}$-evolving $\mathrm{MnFe}_{2} \mathrm{O}_{4}$ nanoparticle-anchored mesoporous silica nanoparticles for efficient photodynamic therapy in hypoxic cancer. J. Am. Chem. Soc. 139, 10992-10995. doi: 10.1021/jacs.7b05559

Klein, S., Kizaloglu, M., Portilla, L., Park, H., Rejek, T., Huemmer, J., et al. (2018). Enhanced in vitro biocompatibility and water dispersibility of magnetite and cobalt ferrite nanoparticles employed as ros formation enhancer in radiation cancer therapy. Small 14:e1704111. doi: 10.1002/smll.2017 04111

Klein, S., Sommer, A., Distel, L. V. R., Hazemann, J.-L., Kroener, W., Neuhuber, W., et al. (2014). Superparamagnetic iron oxide nanoparticles as novel X-ray enhancer for low-dose radiation therapy. J. Phys. Chem. B 118, 6159-6166. doi: $10.1021 /$ jp5026224

Klein, S., Sommer, A., Distel, L. V. R., Neuhuber, W., and Kryschi, C. (2012). Superparamagnetic iron oxide nanoparticles as radiosensitizer via enhanced reactive oxygen species formation. Biochem. Biophys. Res. Commun. 425, 393-397. doi: 10.1016/j.bbrc.2012.07.108

Knowles, H. J., and Harris, A. L. (2001). Hypoxia and oxidative stress in breast cancer hypoxia and tumourigenesis. Breast Cancer Res. 3, 318-322. doi: $10.1186 /$ bcr314
Kojima, K., Takahashi, S., Saito, S., Endo, Y., Nittami, T., Nozaki, T., et al. (2018). Combined effects of $\mathrm{Fe}_{3} \mathrm{O}_{4}$ nanoparticles and chemotherapeutic agents on prostate cancer cells in vitro. Appl. Sci. Basel 8:134. doi: 10.3390/app8010134

Kumar, C. S. S. R., and Mohammad, F. (2011). Magnetic nanomaterials for hyperthermia-based therapy and controlled drug delivery. Adv. Drug Deliv. Rev. 63, 789-808. doi: 10.1016/j.addr.2011.03.008

Kumari, S., Badana, A. K., G, M. M., G, S., and Malla, R. (2018). Reactive oxygen species: a key constituent in cancer survival. Biomark. Insights 13:1177271918755391. doi: 10.1177/1177271918755391

Kuo, S.-H., Wu, P.-T., Huang, J.-Y., Chiu, C.-P., Yu, J., and Liao, M.-Y. (2020). Fabrication of anisotropic $\mathrm{Cu}$ ferrite-polymer core-shell nanoparticles for photodynamic ablation of cervical cancer cells. Nanomaterials 10:2429. doi: 10.3390/nano10122429

Laurent, S., Dutz, S., Haefeli, U. O., and Mahmoudi, M. (2011). Magnetic fluid hyperthermia: focus on superparamagnetic iron oxide nanoparticles. Adv. Colloid Interface Sci. 166, 8-23. doi: 10.1016/j.cis.2011.04.003

Lee, K.-T., Lu, Y.-J., Mi, F.-L., Burnouf, T., Wei, Y.-T., Chiu, S.-C., et al. (2017). Catalase-modulated heterogeneous fenton reaction for selective cancer cell eradication: $\mathrm{SnFe}_{2} \mathrm{O}_{4}$ nanocrystals as an effective reagent for treating lung cancer cells. ACS Appl. Mater. Interfaces 9, 1273-1279. doi: 10.1021 /acsami.6b13529

Li, W.-P., Su, C.-H., Chang, Y.-C., Lin, Y.-J., and Yeh, C.-S. (2016). Ultrasound-induced reactive oxygen species mediated therapy and imaging using a fenton reaction activable polymersome. ACS Nano 10, 2017-2027. doi: 10.1021/acsnano.5b06175

Liang, C., Zhang, X., Cheng, Z., Yang, M., Huang, W., and Dong, X. (2020). Magnetic iron oxide nanomaterials: a key player in cancer nanomedicine. View 1:20200046. doi: 10.1002/VIW.20200046

Liou, G.-Y., and Storz, P. (2010). Reactive oxygen species in cancer. Free Radic. Res. 44, 479-496. doi: 10.3109/10715761003667554

Liu, M., Liu, B., Liu, Q., Du, K., Wang, Z., and He, N. (2019a). Nanomaterialinduced ferroptosis for cancer specific therapy. Coord. Chem. Rev. 382, 160-180. doi: 10.1016/j.ccr.2018.12.015

Liu, X., Yan, B., Li, Y., Ma, X., Jiao, W., Shi, K., et al. (2020). Graphene oxide-grafted magnetic nanorings mediated magnetothermodynamic therapy favoring reactive oxygen species-rebated immune response for enhanced antitumor efficacy. ACS Nano 14, 1936-1950. doi: 10.1021/acsnano.9b08320

Liu, X., Zheng, J., Sun, W., Zhao, X., Li, Y., Gong, N., et al. (2019b). Ferrimagnetic vortex nanoring-mediated mild magnetic hyperthermia imparts potent immunological effect for treating cancer metastasis. ACS Nano 13, 8811-8825. doi: 10.1021/acsnano.9b01979

Liu, X.-L., Chen, S., Zhang, H., Zhou, J., Fan, H.-M., and Liang, X.-J. (2019c). Magnetic nanomaterials for advanced regenerative medicine: the promise and challenges. Adv. Mater. 31:1804922. doi: 10.1002/adma.201804922

Liu, Y., Zhen, W., Jin, L., Zhang, S., Sun, G., Zhang, T., et al. (2018). All-in-one theranostic nanoagent with enhanced reactive oxygen species generation and modulating tumor microenvironment ability for effective tumor eradication. ACS Nano 12, 4886-4893. doi: 10.1021/acsnano.8b01893

Ludwig, R., Teran, F. J., Teichgraeber, U., and Hilger, I. (2017). Nanoparticlebased hyperthermia distinctly impacts production of ROS, expression of Ki-67, TOP2A, and TPX2, and induction of apoptosis in pancreatic cancer. Int. J. Nanomed. 12, 1009-1018. doi: 10.2147/ijn.s108577

Ma, P., Xiao, H., Yu, C., Liu, J., Cheng, Z., Song, H., et al. (2017). Enhanced cisplatin chemotherapy by iron oxide nanocarrier-mediated generation of highly toxic reactive oxygen species. Nano Lett. 17, 928-937. doi: 10.1021/acs.nanolett.6b04269

Ma, X., Wang, Y., Liu, X.-L., Ma, H., Li, G., Li, Y., et al. (2019). $\mathrm{Fe}_{3} \mathrm{O}_{4}-\mathrm{Pd}$ Janus nanoparticles with amplified dual-mode hyperthermia and enhanced ROS generation for breast cancer treatment. Nanoscale Horiz. 4, 1450-1459. doi: $10.1039 / \mathrm{c} 9$ nh00233b

Mai, T., and Hilt, J. Z. (2017). Magnetic nanoparticles: reactive oxygen species generation and potential therapeutic applications. J. Nanopart. Res. 19:253. doi: 10.1007/s11051-017-3943-2

Mai, T., and Hilt, J. Z. (2019). Functionalization of iron oxide nanoparticles with small molecules and the impact on reactive oxygen species generation for potential cancer therapy. Colloids Surf. A-Physicochem. Eng. Aspects 576, 9-14. doi: 10.1016/j.colsurfa.2019.05.003 
Maiti, D., Zhong, J., Zhang, Z., Zhou, H., Xion, S., Dong, Z., et al. (2020). Polyoxomolybdate (POM) nanoclusters with radiosensitizing and scintillating properties for low dose X-ray inducible radiation-radiodynamic therapy. Nanoscale Hori. 5, 109-118. doi: 10.1039/c9nh00374f

Maji, S. K., Mandal, A. K., Nguyen, K. T., Borah, P., and Zhao, Y. (2015). Cancer cell detection and therapeutics using peroxidase-active nanohybrid of gold nanoparticle-loaded mesoporous silica-coated graphene. ACS Appl. Mater. Interfaces 7, 9807-9816. doi: 10.1021/acsami.5b01758

Man, S., Li, M., Zhou, J., Wang, H., Zhang, J., and Ma, L. (2020). Polyethyleneimine coated $\mathrm{Fe}_{3} \mathrm{O}_{4}$ magnetic nanoparticles induce autophagy, NF- $\mathrm{B}$ and TGF$\beta$ signaling pathway activation in $\mathrm{HeLa}$ cervical carcinoma cells via reactive oxygen species generation. Biomater. Sci. 8, 201-211. doi: 10.1039/c9bm01563a

Marycz, K., Maredziak, M., Lewandowski, D., Zachanowicz, E., Ziecina, A., Wiglusz, R. J., et al. (2017). The effect of $\mathrm{Co}_{0.2} \mathrm{Mn}_{0.8} \mathrm{Fe}_{2} \mathrm{O}_{4}$ ferrite nanoparticles on the $\mathrm{C} 2$ canine mastocytoma cell line and adipose-derived mesenchymal stromal stem cells (ASCs) cultured under a static magnetic field: possible implications in the treatment of dog mastocytoma. Cell. Mol. Bioeng. 10, 209-222. doi: 10.1007/s12195-017-0480-0

Min, H., Qi, Y., Zhang, Y., Han, X., Cheng, K., Liu, Y., et al. (2020). A graphdiyne oxide-based iron sponge with photothermally enhanced tumor-specific fenton chemistry. Adv. Mater. 32:2000038. doi: 10.1002/adma.202000038

Murphy, M. P. (2009). How mitochondria produce reactive oxygen species. Biochem. J. 417, 1-13. doi: 10.1042/BJ20081386

Orel, V. E., Tselepi, M., Mitrelias, T., Rykhalskyi, A., Romanov, A., Orel, V. B., et al. (2018). Nanomagnetic modulation of tumor redox state. Nanomed. Nanotechnol. Biol. Med. 14, 1249-1256. doi: 10.1016/j.nano.2018.03.002

Ou, M., Pan, C., Yu, Y., Wang, X., Zhou, Y., Zhang, H., et al. (2020). Two-dimensional highly oxidized ilmenite nanosheets equipped with Z-scheme heterojunction for regulating tumor microenvironment and enhancing reactive oxygen species generation. Chem. Eng. J. 390:124524. doi: 10.1016/j.cej.2020.124524

Pal, S., and Jana, N. R. (2020). Pharmacologic vitamin C-based cell therapy via Iron oxide nanoparticle-induced intracellular fenton reaction. Acs Appl. Nano Mater. 3, 1683-1692. doi: 10.1021/acsanm.9b02405

Pandey, A., Singh, K., Subramanian, S., Korde, A., Singh, R., and Sawant, K. (2020). Heterogeneous surface architectured $\mathrm{pH}$ responsive metal-drug nanoconjugates for mitochondria targeted therapy of glioblastomas: a multimodal intranasal approach. Chem. Eng. J. 394:124419. doi: 10.1016/j.cej.2020.124419

Pardoll, D. M. (2012). The blockade of immune checkpoints in cancer immunotherapy. Nat. Rev. Cancer 12, 252-264. doi: 10.1038/nrc3239

Park, S.-M., Aalipour, A., Vermesh, O., Yu, J. H., and Gambhir, S. S. (2017). Towards clinically translatable in vivo nanodiagnostics. Nat. Rev. Mater. 2:17014. doi: 10.1038/natrevmats.2017.14

Pilar Vinardell, M., and Mitjans, M. (2015). Antitumor activities of metal oxide nanoparticles. Nanomaterials 5, 1004-1021. doi: 10.3390/nano5021004

Prigerson, H. G., Bao, Y., Shah, M. A., Paulk, M. E., LeBlanc, T. W., Schneider, B. J., et al. (2015). Chemotherapy use, performance status, and quality of life at the end of life. JAMA Oncol. 1, 778-784. doi: 10.1001/jamaoncol.2015.2378

Qi, B., Li, Q., and Miao, L. (2016). Achieving enhanced NIR light-induced toxicity via novel hybrid magnetic nanoparticles. RSC Adv 6, 61021-61028. doi: 10.1039/c6ra10513k

Ramalingam, V., Harshavardhan, M., Kumar, S. D., and Devi, S. M. (2020). Wet chemical mediated hematite $\alpha-\mathrm{Fe}_{2} \mathrm{O}_{3}$ nanoparticles synthesis: preparation, characterization and anticancer activity against human metastatic ovarian cancer. J. Alloys Compd. 834:155118. doi: 10.1016/j.jallcom.2020.1 55118

Ranji-Burachaloo, H., Gurr, P. A., Dunstan, D. E., and Qiao, G. G. (2018). Cancer treatment through nanoparticle-facilitated fenton reaction. ACS Nano 12, 11819-11837. doi: 10.1021/acsnano.8b07635

Sahu, N. K., Gupta, J., and Bahadur, D. (2015). PEGylated FePt-Fe ${ }_{3} \mathrm{O}_{4}$ composite nanoassemblies (CNAs): in vitro hyperthermia, drug delivery and generation of reactive oxygen species (ROS). Dalton Trans. 44, 9103-9113. doi: $10.1039 / \mathrm{c} 4 \mathrm{dt} 03470 \mathrm{~h}$

Schumacker, P. T. (2006). Reactive oxygen species in cancer cells: live by the sword, die by the sword. Cancer Cell 10, 175-176. doi: 10.1016/j.ccr.2006.08.015

Shaikh, S., Younis, M., Rehman, F. U., Jiang, H., and Wang, X. (2020). Specific oxide nanoclusters enhance intracellular reactive oxygen species for cancertargeted therapy. Langmuir 36, 9472-9480. doi: 10.1021/acs.langmuir.0c01378
Sharma, R. A., Plummer, R., Stock, J. K., Greenhalgh, T. A., Ataman, O., Kelly, S., et al. (2016). Clinical development of new drug-radiotherapy combinations. Nat. Rev. Clin. Oncol. 13, 627-642. doi: 10.1038/nrclinonc.2016.79

Shen, Z., Liu, T., Li, Y., Lau, J., Yang, Z., Fan, W., et al. (2018). Fenton-reactionacceleratable magnetic nanoparticles for ferroptosis therapy of orthotopic brain tumors. ACS Nano 12, 11355-11365. doi: 10.1021/acsnano.8b06201

Shi, J., Kantoff, P. W., Wooster, R., and Farokhzad, O. C. (2017). Cancer nanomedicine: progress, challenges and opportunities. Nat. Rev. Cancer 17, 20-37. doi: 10.1038/nrc.2016.108

Shi, Y., Wang, J., Liu, J., Lin, G., Xie, F., Pang, X., et al. (2020). Oxidative stress-driven DR5 upregulation restores TRAIL/Apo2L sensitivity induced by iron oxide nanoparticles in colorectal cancer. Biomaterials 233:119753. doi: 10.1016/j.biomaterials.2019.119753

Siddiqui, M. A., Wahab, R., Ahmad, J., Farshori, N. N., and Al-Khedhairy, A. A. (2020). Single and multi-metal oxide nanoparticles induced cytotoxicity and ROS generation in human breast cancer (MCF-7) cells. J. Inorg. Organomet. Polym. Mater. 30, 4106-4116. doi: 10.1007/s10904-020-01564-z

Silva, A. C., Oliveira, T. R., Mamani, J. B., Malheiros, S. M. F., Malavolta, L., Pavon, L. F., et al. (2011). Application of hyperthermia induced by superparamagnetic iron oxide nanoparticles in glioma treatment. Int. J. Nanomed. 6, 591-603. doi: 10.2147/IJN.S14737

Song, J., Lin, L., Yang, Z., Zhu, R., Zhou, Z., Li, Z.-W., et al. (2019). Selfassembled responsive bilayered vesicles with adjustable oxidative stress for enhanced cancer imaging and therapy. J. Am. Chem. Soc. 141, 8158-8170. doi: $10.1021 /$ jacs.8b13902

Sullivan, R., Alatise, O. I., Anderson, B. O., Audisio, R., Autier, P., Aggarwal, A., et al. (2015). Global cancer surgery: delivering safe, affordable, and timely cancer surgery. Lancet Oncol. 16, 1193-1224. doi: 10.1016/S1470-2045(15)00223-5

Swietek, M., Panchuk, R., Skorokhyd, N., Cernoch, P., Finiuk, N., Klyuchivska, O., et al. (2020). Magnetic temperature-sensitive solid-lipid particles for targeting and killing tumor cells. Front. Chem. 8:205. doi: 10.3389/fchem.2020.00205

Tarangelo, A., and Dixon, S. J. (2016). An iron age for cancer therapy. Nat. Nanotechnol. 11, 921-922. doi: 10.1038/nnano.2016.199

Thenmozhi, T. (2020). Functionalization of iron oxide nanoparticles with clove extract to induce apoptosis in MCF-7 breast cancer cells. 3 Biotech 10:82. doi: 10.1007/s13205-020-2088-7

Thoidingjam, S., and Tiku, A. B. (2019). Therapeutic efficacy of Phyllanthus emblica-coated iron oxide nanoparticles in A549 lung cancer cell line. Nanomedicine 14, 2355-2371. doi: 10.2217/nnm-2019-0111

Topalian, S. L., Hodi, F. S., Brahmer, J. R., Gettinger, S. N., Smith, D. C., McDermott, D. F., et al. (2012). Safety, activity, and immune correlates of anti-PD-1 antibody in cancer. N. Engl. J. Med. 366, 2443-2454. doi: 10.1056/NEJMoa1200690

Trachootham, D., Alexandre, J., and Huang, P. (2009). Targeting cancer cells by ROS-mediated mechanisms: a radical therapeutic approach? Nat. Rev. Drug Disc. 8, 579-591. doi: 10.1038/nrd2803

Vahrmeijer, A. L., Hutteman, M., van der Vorst, J. R., van de Velde, C. J. H., and Frangioni, J. V. (2013). Image-guided cancer surgery using near-infrared fluorescence. Nat. Rev. Clin. Oncol. 10, 507-518. doi: 10.1038/nrclinonc.2013.123

Wang, P., Shi, Y., Zhang, S., Huang, X., Zhang, J., Zhang, Y., et al. (2019a). Hydrogen peroxide responsive iron-based nanoplatform for multimodal imaging-guided cancer therapy. Small 15:1803791. doi: 10.1002/smll.201803791

Wang, S., Luo, J., Zhang, Z., Dong, D., Shen, Y., Fang, Y., et al. (2018). Iron and magnetic: new research direction of the ferroptosis-based cancer therapy. Am. J. Cancer Res. 8, 1933-1946.

Wang, S., Wang, Z., Yu, G., Zhou, Z., Jacobson, O., Liu, Y., et al. (2019b). Tumor-specific drug release and reactive oxygen species generation for cancer chemo/chemodynamic combination therapy. Adv. Sci. 6:1801986. doi: 10.1002/advs.201801986

Wang, Z., Ju, Y., Ali, Z., Yin, H., Sheng, F., Lin, J., et al. (2019c). Nearinfrared light and tumor microenvironment dual responsive size-switchable nanocapsules for multimodal tumor theranostics. Nat. Commun. 10:4418. doi: 10.1038/s41467-019-12142-4

Winston, G. W., and Giulio, R. T. D. (1991). Prooxidant and antioxidant mechanisms in aquatic organisms. Aquatic Toxicol. 19, 137-161. 
Wu, H., Liu, L., Song, L., Ma, M., Gu, N., and Zhang, Y. (2019). Enhanced tumor synergistic therapy by injectable magnetic hydrogel mediated generation of hyperthermia and highly toxic reactive oxygen species. ACS Nano 13, 14013-14023. doi: 10.1021/acsnano.9b06134

Wu, H., Yin, J.-J., Wamer, W. G., Zeng, M., and Lo, Y. M. (2014). Reactive oxygen species-related activities of nano-iron metal and nano-iron oxides. J. Food Drug Analy. 22, 86-94. doi: 10.1016/j.jfda.2014.01.007

Xie, Y., Jiang, J., Tang, Q., Zou, H., Zhao, X., Liu, H., et al. (2020). Iron oxide nanoparticles as autophagy intervention agents suppress hepatoma growth by enhancing tumoricidal autophagy. Adv. Sci. 7:1903323. doi: 10.1002/advs.201903323

Xie, Y., Liu, D., Cai, C., Chen, X., Zhou, Y., Wu, L., et al. (2016). Size-dependent cytotoxicity of $\mathrm{Fe}_{3} \mathrm{O}_{4}$ nanoparticles induced by biphasic regulation of oxidative stress in different human hepatoma cells. Int. J. Nanomed. 11, 3557-3570. doi: 10.2147/IJN.S105575

Xiong, R., Zhang, W., Zhang, Y., Zhang, Y., Chen, Y., He, Y., et al. (2019). Remote and real time control of an FVIO-enzyme hybrid nanocatalyst using magnetic stimulation. Nanoscale 11, 18081-18089. doi: 10.1039/c9nr04289j

Yanagie, H., Ogata, A., Mitsui, S., Hisa, T., Yamase, T., and Eriguchi, M. (2006). Anticancer activity of polyoxomolybdate. Biomed. Pharmacother. 60, 349-352. doi: 10.1016/j.biopha.2006.06.018

Yang, C.-T., Li, K.-Y., Meng, F.-Q., Lin, J.-F., Young, I.-C., Ivkov, R., et al. (2018). ROS-induced HepG2 cell death from hyperthermia using magnetic hydroxyapatite nanoparticles. Nanotechnology 29:375101. doi: 10.1088/1361-6528/aacda1

Yang, K., Zhang, S., Zhang, G., Sun, X., Lee, S.-T., and Liu, Z. (2010). Graphene in mice: ultrahigh in vivo tumor uptake and efficient photothermal therapy. Nano Lett. 10, 3318-3323. doi: 10.1021/nl100996u

Ye, P., Ye, Y., Chen, X., Zou, H., Zhou, Y., Zhao, X., et al. (2020). Ultrasmall $\mathrm{Fe}_{3} \mathrm{O}_{4}$ nanoparticles induce $S$-phase arrest and inhibit cancer cells proliferation. Nanotechnol. Rev. 9, 61-69. doi: 10.1515/ntrev-2020-0006

Yin, S.-Y., Song, G., Yang, Y., Zhao, Y., Wang, P., Zhu, L.-M., et al. (2019). Persistent regulation of tumor microenvironment via circulating catalysis of $\mathrm{MnFe}_{2} \mathrm{O}_{4} @$ metal-organic frameworks for enhanced photodynamic therapy. Adv. Funct. Mater. 29:1901417. doi: 10.1002/adfm.201901417

You, C., Gao, Z., Wu, H., Sun, K., Ning, L., Lin, F., et al. (2019). Reactive oxygen species mediated theranostics using a Fenton reaction activable lipopolymersome. J. Mater. Chem. B 7, 314-323. doi: 10.1039/c8tb02947d

Yu, J., Zhao, F., Gao, W., Yang, X., Ju, Y., Zhao, L., et al. (2019). Magnetic reactive oxygen species nanoreactor for switchable magnetic resonance imaging guided cancer therapy based on $\mathrm{pH}$-sensitive $\mathrm{Fe}_{5} \mathrm{C}_{2} @ \mathrm{Fe}_{3} \mathrm{O}_{4}$ nanoparticles. ACS Nano 13, 10002-10014. doi: 10.1021/acsnano.9b01740
Zanganeh, S., Hutter, G., Spitler, R., Lenkov, O., Mahmoudi, M., Shaw, A., et al. (2016). Iron oxide nanoparticles inhibit tumour growth by inducing proinflammatory macrophage polarization in tumour tissues. Nat. Nanotechnol. 11, 986-994. doi: 10.1038/nnano.2016.168

Zhang, D., Zhao, Y.-X., Gao, Y.-J., Gao, F.-P., Fan, Y.-S., Li, X.-J., et al. (2013). Anti-bacterial and in vivo tumor treatment by reactive oxygen species generated by magnetic nanoparticles. J. Mater. Chem. B 1, 5100-5107. doi: 10.1039/c3tb20907e

Zhang, P., Wu, G., Zhao, C., Zhou, L., Wang, X., and Wei, S. (2020a). Magnetic stomatocyte-like nanomotor as photosensitizer carrier for photodynamic therapy based cancer treatment. Colloids Surf. B-Biointerfaces 194:111204. doi: 10.1016/j.colsurfb.2020.111204

Zhang, T., Li, Y., Hong, W., Chen, Z., Peng, P., Yuan, S., et al. (2019). Glucose oxidase and polydopamine functionalized iron oxide nanoparticles: combination of the photothermal effect and reactive oxygen species generation for dual-modality selective cancer therapy. J. Mater. Chem. B 7, 2190-2200. doi: $10.1039 / \mathrm{c} 8 \mathrm{tb} 03320 \mathrm{j}$

Zhang, Y., Fu, X., Jia, J., Wikerholmen, T., Xi, K., Kong, Y., et al. (2020b). Glioblastoma therapy using codelivery of cisplatin and glutathione peroxidase targeting siRNA from iron oxide nanoparticles. ACS Appl. Mater. Interfaces 12, 43408-43421. doi: 10.1021/acsami.0c12042

Zhang, Y., Hai, Y., Miao, Y., Qi, X., Xue, W., Luo, Y., et al. (2020c). The toxicity mechanism of different sized iron nanoparticles on human breast cancer (MCF7) cells. Food Chem. 341, 128263-128263. doi: 10.1016/j.foodchem.2020.128263

Zhang, Y., Xu, Y., Sun, D., Meng, Z., Ying, W., Gao, W., et al. (2020d). Hollow magnetic nanosystem-boosting synergistic effect between magnetic hyperthermia and sonodynamic therapy via modulating reactive oxygen species and heat shock proteins. Chem. Eng. J. 390:124521. doi: $10.1016 /$ j.cej.2020.124521

Conflict of Interest: The authors declare that the research was conducted in the absence of any commercial or financial relationships that could be construed as a potential conflict of interest.

Copyright (C) 2021 Yu, Zhang, Zhang, Zhong and Fan. This is an open-access article distributed under the terms of the Creative Commons Attribution License (CC BY). The use, distribution or reproduction in other forums is permitted, provided the original author(s) and the copyright owner(s) are credited and that the original publication in this journal is cited, in accordance with accepted academic practice. No use, distribution or reproduction is permitted which does not comply with these terms. 